\title{
THE EFFECT OF TEMPERATURE ON THE LINEAR DIMENSIONAL STABILITY OF ELASTOMERS.
}

\section{Dr. Susan Sanette Muller}

A Mini-thesis submitted in partial fulfillment of the requirements for the degree of Master Chirurgiae Dentium (MChD) in the Department of Restorative Dentistry, Faculty of Oral Health Sciences and WHO Oral Health Collaborating Centre,

University of the Western Cape

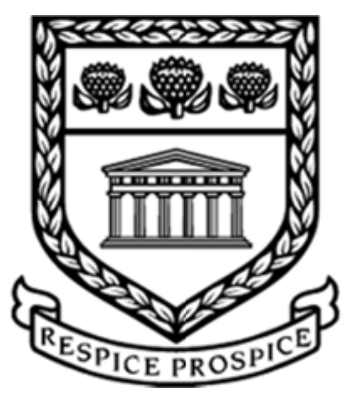

Supervisor

Professor GAVM Geerts

February 2012 


\section{DECLARATION}

I hereby declare that "The effect of temperature on linear dimensional stability of elastomers" is my own work, that it has not been submitted before for any degree or examination in this or any other university, and that all the sources I have used or quoted have been indicated and acknowledged as complete references.

\section{Dr. Susan Sanette Muller}

Signed:

This $2^{\text {th }}$ day of August, 2012 


\section{DEDICATION}

To my loving husband and best friend Anton Muller for the great sacrifice he made to take care of our lovely children while I was studying, for his never ending support and encouragement throughout the course and for believing in me.

To my children, Ruben, Simone and Zander for your unconditional love, you are my light.

To my parents, brother and sister, relatives, friends and colleagues who supported me through the course of this degree.

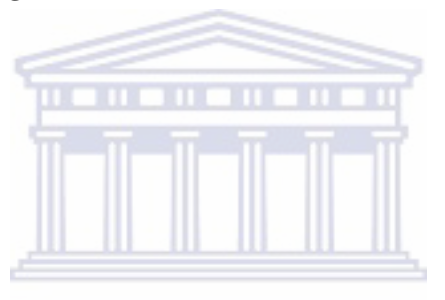




\section{ACKNOWLEDGEMENTS}

I wish to express my sincere gratitude to the following people for their unconditional assistance in developing this research project.

Professor GAVM Geerts for her supervision, continued support, guidance, inspiration and encouragement throughout this research project.

Professor Grobler S, Dr. Rossouw R, and Dr. Basson, for their advice and technical expertise and for the use of their laboratories in the performance of this study.

Professor M Kidd for his help in the statistical analysis of the data.

Professor Madsen for his statistical advice.

Dr Rob Barry for his input and advice regarding academic writing.

For Wright Millners (South Africa, Cape Town) for their donations of materials used in this study.

I greatly acknowledge the support of all the staff in the Department of Restorative Dentistry especially Professor Geerts, Dr N. Patel, Professor Wilson. 


\section{ABSTRACT}

Title: The effect of temperature on linear dimensional stability of elastomers.

Objectives: Sometimes, dental impressions need to be transported to distant laboratories. It has been reported that the temperature in a vehicle can reach up to $66^{\circ} \mathrm{C}$ when the outdoor temperature is $38^{\circ} \mathrm{C}$. These temperatures may be reached during South African summers. The objective of this in vitro study was to investigate the effect of temperature and time on the dimensional stability of two elastomeric impression materials.

Methodology: Specimens consisted of impressions made of an ISO-specified test-block featuring a pattern of grooves. Materials used were polyether (Impregum Penta) and polyvinylsiloxane (Affinis Precious regular body). Using an SLR camera and standardized technique, the specimens were photographed at 2 different temperatures $\left(21^{\circ} \mathrm{C}\right.$ and $\left.66^{\circ} \mathrm{C}\right)$ and 3 time intervals (30min, 8hrs and 14 days). This resulted in a total of 12 groups $(n=10)$ to be compared. Digital images of the impressions were calibrated and measured using digital analyzing software. These distances were used to evaluate the mean \% dimensional change (\%DC) for each group. VEPAC module of Statistica 10 was used for the statistical analysis. To analyze exactly where the differences lied, a Fisher LSD correction was applied to correct for multiple pair wise comparisons.

Results: Comparing polyether with silicone, there was no difference in the mean \%DC for specimens kept at $21^{\circ} \mathrm{C}$ for $8 \mathrm{hrs}$ (polyether $=0.364$; silicone $=0.237$ ). Neither was there a difference between polyether and silicone when heated to $66^{\circ} \mathrm{C}$, cooled off, and measured 
after 8hrs (polyether=0.306; silicone $=0.297$ ) or after 14 days (polyether=-0.272; silicone=0.093).

For both polyether and silicone, the mean $\% \mathrm{DC}$ of the groups exposed to $66^{\circ} \mathrm{C}$, cooled off and measured after 8hrs (polyether=0.306; silicone=0.297) differed significantly when compared to the group measured after 14 days (polyether $=-0.2723$; silicone $=-0.092$ ) $(\mathrm{P}<0.0001$ and $\mathrm{P}=0.0029$ resp $)$.

For both polyether and silicone, the mean $\% \mathrm{DC}$ of the groups exposed to $66^{\circ} \mathrm{C}$, cooled off and measured after 8hrs (polyether=0.306; silicone=0.297) did not differ when compared to the $21^{\circ} \mathrm{C}$ (polyether $=0.364$; silicone $=0.237$ ).

Conclusions: Within limitations of this study, both materials were heat-sensitive. It is recommended that materials return to $21^{\circ} \mathrm{C}$ before casting. Despite statistical differences, all results were within ISO specifications of maximum 1.5\%DC. 


\section{KEYWORDS}

Impression materials

Elastomers

Linear dimensional stability

Temperature

Time

Digital image analysis

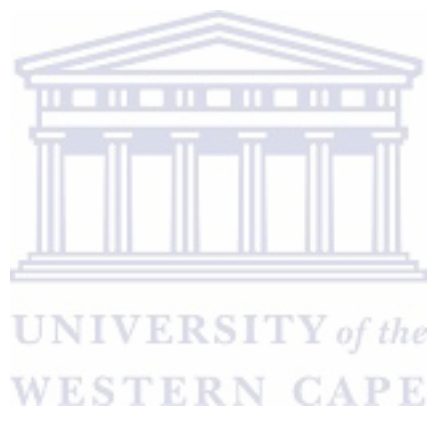




\section{DEFINITIONS}

For the purpose of this study the following terms will be defined based on the Glossary of Prosthodontics Terms (2005):

Elastomeric impression material: a group of flexible chemical polymers, which are either chemically or physically cross-linked. Generally, they can be easily stretched and rapidly recover their original dimensions when applied stresses are released.

Dimensional stability: the ability of a material to retain its size and form over time.

Impression material: any substance or combination of substances used for making an impression or negative reproduction. 


\section{TABLE OF CONTENTS}

TITLE PAGE i i

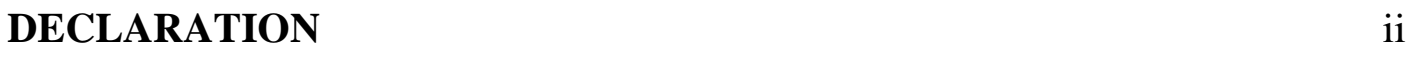

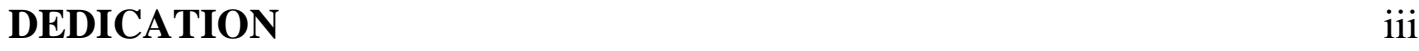

ACKNOWLEDGEMENTS iv

ABSTRACT

KEYWORDS vii

DEFINITIONS viii

TABLE OF CONTENTS IX ix

LIST OF TABLES Xii

LIST OF FIGURES Xiii

CHAPTER 1: INTRODUCTION AND LITERATURE REVIEW

1.1 Introduction UNIVERSITY of the 1

1.2 Literature review 2

1.2.1 Impression materials used in dentistry 2

1.2.2 Properties of impression materials 2

Ideal properties $\quad 2$

Accuracy $\quad 5$

Dimensional stability

1.2.3 Testing of elastomeric impression materials 9

$\begin{array}{ll}\text { Methods } & 9\end{array}$

$\begin{array}{ll}\text { Standards } & 10\end{array}$

$\begin{array}{ll}1.3 \text { Conclusion } & 11\end{array}$ 


\section{CHAPTER 2: AIMS AND OBJECTIVES}

2.1 Aim

2.2 Objectives 12

$\begin{array}{ll}2.3 \text { Null-hypotheses } & 12\end{array}$

\section{CHAPTER 3: MATERIALS AND METHODS}

$\begin{array}{ll}3.1 \text { Introduction } & 13\end{array}$

$\begin{array}{ll}\text { 3.2 Methodology } & 13\end{array}$

3.2.1 Stainless steel test block 13

$\begin{array}{ll}\text { 3.2.2 Impression materials } & 15\end{array}$

3.2.3 Groups 15

3.2.4 Specimen fabrication -16

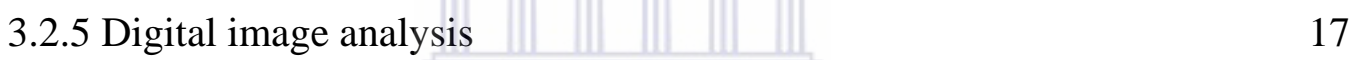

3.3 Data analysis UNIVERSITY of the 19

\section{CHAPTER 4: RESULTS}

$\begin{array}{ll}4.1 \text { Introduction } & 21\end{array}$

$\begin{array}{ll}\text { 4.2 Descriptive analysis } & 21\end{array}$

$\begin{array}{lr}4.3 \text { Statistical analysis } & 23\end{array}$

\section{CHAPTER 5: DISCUSSION AND CONCLUSION}

$\begin{array}{ll}\text { 5.1 Discussion of the results } & 29\end{array}$

$\begin{array}{ll}5.2 \text { Limitations } & 34\end{array}$

$\begin{array}{ll}5.3 \text { Conclusions } & 34\end{array}$

$\begin{array}{ll}\text { REFERENCES } & 36\end{array}$ 


\section{ADDENDA}

Addendum 1: Materials specifications Affinis \& Impregum

Addendum 2: Digital measuring sequence using AnalysingDigitalImaging

software version (Accessed and downloaded 1 February 2011).

Addendum 3: Data capturing sheet

Addendum 4: Raw data (dimensions \& \%DC)

Addendum 5: Multiple comparisons

Addendum 6: Descriptive statistics

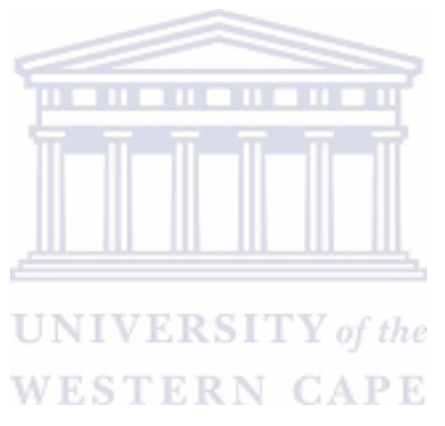




\section{LIST OF TABLES}

Table 1.1 Elastic impression materials

Table 3.1 Exposure to temperature, time interval between impression taking, reading and conditions at which readings are made

Table 4.1 Summary of the descriptive statistics (\%DC) for the polyether impression material (P)

Table 4.2 Summary of the descriptive statistics (\%DC) for the silicone impression material (S)

Table 4.3 Fixed effect test for \%DC

Table 4.4 Pairs of groups and p-values to demonstrate the effect of different materials on the \%DC

Table 4.5 Pairs of groups and p-values to demonstrate the effect of time on the \%DC

Table 4.6 Pairs of groups and p-values to demonstrate the effect of exposure to temperature on the \%DC

Table 4.7 Pairs of groups and p-values to demonstrate the effect of temperature of the specimens at the time of reading on the \%DC 


\section{LIST OF FIGURES}

Figure 3.1 Measuring the distance between line no. 4 and 5 along

line 3 (ISO 4823) 14

Figure 3.2 Mounting of the camera and specimen for the digital imaging 18

$\begin{array}{lll}\text { Figure 3.3 Image of a specimen with calibrating ruler } & 18\end{array}$

Figure 4.4 Effect of different materials on the \%DC 24

Figure 4.5 The effect of time on the mean \%DC 25

Figure 4.6 The effect of temperature on the \%DC 26

Figure 4.7 The effect of temperature and time on the mean \%DC 27

Figure 4.8 Mean \%DC for time, temperature and materials 28 


\section{CHAPTER 1. \\ INTRODUCTION AND LITERATURE REVIEW}

\subsection{INTRODUCTION}

Impression materials are used in dentistry to make impressions of the teeth and surrounding structures. These impressions are used to manufacture diagnostic and master casts. Diagnostic casts are used to assist in treatment planning, while master casts are used to manufacture complete or partial removable prosthesis, fixed partial prosthesis and implant-supported prosthesis. These procedures cover most aspects of a prosthodontic practice, including intra-oral and extra-oral prostheses.

Even though new technology allows digital impression making, it is not expected that this technology will substitute traditional impression making in the foreseeable future.

Making impressions and casts is a complex procedure, requiring accuracy in the handling of a number of materials, such as tray materials, tray adhesives, impression materials, dental stones, as well as using appropriate clinical and laboratory techniques. The quality of the impression is crucial for the fit of the definitive prosthesis and contributes to the long-term success of the dental reconstruction. Information supplied by manufacturers should be tested and supported by independent research. Since dental materials are continuously modified in an effort to improve their clinical performance, independent research should also be ongoing. 


\subsection{LITERATURE REVIEW}

\subsubsection{IMPRESSION MATERIALS USED IN DENTISTRY}

There are several types of elastomeric impression materials available for dental use. Table 1.1 (Rosentiel et al., 2006) provides a list of the categories of impression materials for dental impression making. For work requiring a high level of fit, such as for fixed - and implant prosthodontics, the materials of choice are the polyvinyl siloxane and polyether impression materials, because they have a reputation for being accurate and dimensionally stable.

\subsubsection{PROPERTIES OF IMPRESSION MATERIALS}

\section{Ideal properties}

The search for an ideal impression material is ongoing. The properties of interest for impression materials include: detail reproduction, dimensional stability, elastic recovery, flexibility, flow, hydrophilicity, patient comfort, a long shelf life and economics (Donovan and Chee, 2004). Impression materials differ in relation to ideal properties, but these differences can provide a basis for selecting the most appropriate impression material for a specific clinical situation: one single impression material does not fit every clinical situation ideally. Table 1.1 (Rosentiel et al., 2006) highlights the most relevant advantages, disadvantages and clinical applications of the different categories of impression materials. 
Of course, the best possible material properties should be supported by the correct manipulation of the materials. Issues to be considered should be: adequate mixing, creating a uniform bulk, control over viscosity, tray selection, achieving adhesion to the tray and correct pouring of the impression (Donovan and Chee, 2004).

The International Standard Organization (ISO) classifies elastomeric impression materials according to consistencies determined directly after completion of mixing according to manufacturer’s instructions (ISO 4823:2000):

Type 0: $\quad$ putty consistency

Type 1: $\quad$ heavy-bodied consistency

Type 2: $\quad$ medium-bodied consistency

Type 3: $\quad$ light-bodied consistency

According to ISO, type 0 (putty) and type 1 (heavy-bodied) materials produce an indent $\leq 35 \mu \mathrm{m}$ when subjected to a consistency test. Impressions with these materials should be made in one or two steps. Type 2 (medium-bodied) materials produce an indent between 31 to $41 \mu \mathrm{m}$, and impressions are made in one step. Type 3 (light-bodied) materials produce an indent of $\geq 36 \mu \mathrm{m}$, and a syringe is used for making the impression (ISO 4823, 2000). The viscosity of the setting material influences the accuracy or detail reproduction of an impression (Hamalian et al, 2011). 


\begin{tabular}{|c|c|c|c|c|}
\hline Materials & Advantages & Disadvantages & $\begin{array}{l}\text { Recommended } \\
\text { use }\end{array}$ & Precautions \\
\hline $\begin{array}{l}\text { Reversible } \\
\text { hydrocolloid }\end{array}$ & $\begin{array}{l}\text { Hydrophilic } \\
\text { Long working } \\
\text { time } \\
\text { Low cost }\end{array}$ & $\begin{array}{l}\text { Low tear } \\
\text { resistance } \\
\text { Low stability } \\
\text { Special equipment } \\
\text { needed } \\
\text { Advanced } \\
\text { preparation } \\
\text { required }\end{array}$ & $\begin{array}{l}\text { Multiple } \\
\text { preparations } \\
\text { Problem with } \\
\text { moisture }\end{array}$ & $\begin{array}{l}\text { Pour immediately } \\
\text { Use stone only }\end{array}$ \\
\hline $\begin{array}{l}\text { Irreversible } \\
\text { hydrocolloid }\end{array}$ & $\begin{array}{l}\text { Rapid set } \\
\text { Easy } \\
\text { manipulation } \\
\text { Patient acceptance } \\
\text { Low cost }\end{array}$ & $\begin{array}{l}\text { Pour once with } \\
\text { reasonable } \\
\text { accuracy } \\
\text { Limited accuracy } \\
\text { and surface detail } \\
\text { reproduction }\end{array}$ & $\begin{array}{l}\text { Diagnostic casts } \\
\text { Not for working } \\
\text { casts. }\end{array}$ & Pour immediately. \\
\hline $\begin{array}{l}\text { Polysulphide } \\
\text { polymer }\end{array}$ & $\begin{array}{l}\text { High tear strength } \\
\text { Comparatively } \\
\text { easier to pour than } \\
\text { other elastomers } \\
\text { Accurate through } \\
\text { third pour if } \\
\text { poured } \\
\text { immediately }\end{array}$ & $\begin{array}{l}\text { Unpleasant odour } \\
\text { Long setting time } \\
\text { Stability not so } \\
\text { fair } \\
\text { Distortion over } \\
\text { time } \\
\text { Hydrophobic }\end{array}$ & Most impressions & $\begin{array}{l}\text { Pour within } 1 \\
\text { hour. Allow to set } \\
\text { for } 10 \text { minutes }\end{array}$ \\
\hline Polyether & $\begin{array}{l}\text { Short setting time } \\
\text { Auto-mix } \\
\text { available } \\
\text { Excellent } \\
\text { dimensional } \\
\text { stability and } \\
\text { accuracy } \\
\text { Acceptable for } \\
\text { implant } \\
\text { impressions }\end{array}$ & $\begin{array}{l}\text { Set material rigid, } \\
\text { Imbibition } \\
\text { Short working of } \\
\text { time }\end{array}$ & $\begin{array}{l}\text { Most impressions } \\
\text { E }\end{array}$ & $\begin{array}{l}\text { Care not to break } \\
\text { teeth when } \\
\text { separating from } \\
\text { cast. }\end{array}$ \\
\hline $\begin{array}{l}\text { Addition-cured } \\
\text { silicone }\end{array}$ & $\begin{array}{l}\text { Short setting time } \\
\text { Auto-mix } \\
\text { available } \\
\text { Pleasant to use } \\
\text { Excellent } \\
\text { dimensional } \\
\text { stability }\end{array}$ & $\begin{array}{l}\text { Hydrophobic } \\
\text { Poor wetting } \\
\text { Some materials } \\
\text { release } \mathrm{H}_{2}\end{array}$ & Most impressions & $\begin{array}{l}\text { Delayed pour of } \\
\text { some materials } \\
\text { Care to avoid } \\
\text { bubbles when } \\
\text { pouring }\end{array}$ \\
\hline $\begin{array}{l}\text { Condensation- } \\
\text { cured silicone }\end{array}$ & $\begin{array}{l}\text { Short setting time } \\
\text { Easy to use }\end{array}$ & $\begin{array}{l}\text { Hydrophobic } \\
\text { Poor wetting } \\
\text { Low dimensional } \\
\text { stability }\end{array}$ & Most impressions & $\begin{array}{l}\text { Pour immediately } \\
\text { Care not to incor- } \\
\text { perate bubbles }\end{array}$ \\
\hline
\end{tabular}


Two important properties of impression materials that contribute to an accurate reproduction of teeth and surrounding tissues are detail reproduction and dimensional stability. These properties will be discussed in the next two paragraphs.

\section{Accuracy}

The accuracy of an impression material has 2 aspects: detail reproduction and dimensional accuracy. Although no definition for detail reproduction was found, the American Dental Association specification \#19 prescribes that elastomeric impression materials should produce fine detail of $25 \mu \mathrm{m}$ or less. The ISO requires a continuous line width reproduction of 75,50 , and $20 \mu \mathrm{m}$ depending on the viscosity of the material. As mentioned earlier, the viscosity of the setting material influences the accuracy or detail reproduction of an impression (Hamalian et al, 2011). Derrien and Le Menn (1995 cited in Pant et al., 2008) mentioned that polyvinyl siloxane impression materials could reproduce detail of 1 to $2 \mu \mathrm{m}$. However, if conventional impressions and casts are used for fabricating indirect restorations, this level of accuracy of impression materials is largely lost because dental stone cannot reproduce detail finer than $20 \mu \mathrm{m}$. The dimension of gypsum crystals ranges from $15-25 \mu \mathrm{m}$. Detail reproduction of polyvinyl siloxane impression materials is time and product dependent (Pant et al., 2008).

\section{Dimensional stability}

Dimensional stability differs from dimensional accuracy in the sense that 
dimensional stability measures change over time. The Glossary of Prosthodontic Terms (2005) defines dimensional stability as the ability of a material to retain its size and form over time. An ideal impression material should be dimensionally stable reflecting its property to be dimensionally accurate at any given time after impression making, allowing the operator to pour it at any convenient time.

Because of its time-dependency the greatest dimensional accuracy occurs immediately after polymerization (Rubel, 2007). Accuracy is lost with extended periods of time (Schen, 2003; Donovan and Chee, 2004), because of lack of dimensional stability. Polyether and polyvinyl siloxane are accurate for $1-2$ weeks, whereas polysulfide is accurate if the impression is casted within between 1 - 2 hours (Williams et al, 1984; Schen, 2003) of impression making. Therefore, should pouring be delayed, it is advisable to use addition-silicone or polyether materials, which have the smallest dimensional change over time.

Elastomeric impression materials are considered to be more dimensionally stable than hydrocolloid impression materials. Hydrocolloid materials should be poured within 10 minutes after removal from the mouth. These materials are composed of $80 \%$ water and are subject to syneresis (evaporation of water) and imbibition (absorption of water), resulting in distortion. Therefore it is important to avoid wrapping these impressions in a wet paper towel, as seems to be common practice. This may result in absorption of water from the paper towel and cause distortion of the impression (Donovan and Chee, 2004).

Even though they are considered to be superior to hydrocolloids in terms of dimensional stability, elastomers are subject to small changes. All currently available elastomeric impression materials undergo polymerization shrinkage (Rubel, 2007). This is caused by the rearrangement of the bonds during 
polymerization. Additional shrinkage may occur when unstable by-products, formed during polymerization, evaporate. Therefore, polysulfide impression materials and condensation silicones have the largest dimensional change during setting. Polyethers exhibit a slight change, whereas additional silicones have the smallest change. The shrinkage for these two products is lower because there is no loss of by-products. (Williams et al., 1984; Anusavice, 2003; Donavan and Chee, 2004)

Addition-silicones acquire almost the ideal dimensional stability because there are no by-products formed during the chemical setting reaction. It can be poured immediately after the impression has been removed from the oral cavity, or days after impression making and can still produce an accurate cast if poured within 1 2 weeks (Donovan and Chee, 2004). Marcinak and Draughn (1982) investigated delayed pour for up to 1 week and found no significant change $(-0.3 \%)$ with addition-cured silicones. Williams et al. (1984) and Johnson and Craig (1986) agreed and reported that addition-cured silicones were the most accurate after delayed pour of elastomeric impression materials.

Chen et al. (2004) investigated storage time and filler loading of elastomers and found the greatest accuracy on polyvinyl siloxane and highly-filled materials.

Condensation silicones produce ethyl alcohol, and polysulfide rubber impression materials produce water as a by-product as a result of the setting reaction (Donovan and Chee, 2004). These by-products can evaporate from the surface of the set impression. Over time these materials shrink. Therefore impressions made of these materials should be poured in less than 30 minutes after removal from the mouth to prevent distortion. In 1981, Lacy et al. investigated delayed pour of elastomers and 
concluded condensation silicone systems should be poured as soon as possible after making the impression.

Polyether impression materials are subject to imbibition. This material swells over time due to water absorption from the atmosphere, resulting in a distorted impression (Lacy et al., 1981; Williams et al., 1984). It is recommended that for optimal accuracy polyether impression materials should be poured within 60 minutes after removal from the mouth (Donovan and Chee, 2004). Due to its property of absorbing water from the atmosphere, care should be taken not to store polyether impression material together with water-based impression materials when sending impressions to a distant laboratory.

It appears that temperature also has an influence on accuracy of impression materials. Impression materials set at body temperature. However, after removal from the mouth, they acquire room temperature. De Araujo and Jorgensen, (1986) found improved accuracy by reheating addition-reaction silicone impression, from room temperature to $37^{\circ} \mathrm{C}$. If even these relatively small temperature changes have an effect on accuracy, what would the effect be of larger temperature fluctuations? Purk et al., (1998) investigated elastomers under extreme temperature and storage time. He found that all elastomers were unstable under extreme temperatures. According to Purk et al. (1998), it is not unusual for parcels to stay in delivery vehicles for more than eight hours during the delivery process. It has been reported that the temperature in a delivery vehicle can reach up to $66^{\circ} \mathrm{C}$ when the outdoor temperature is $38^{\circ} \mathrm{C}$. During South African summers, these outside temperatures can be reached. 
Corso et al., (1998) tested the effect of temperature changes on the dimensional stability of polyvinyl siloxane and polyether impression materials. They found that changes in storage temperature had a statistically significant effect on the dimensional stability of horizontal and vertical lines. Overall dimensional changes were very small. These measurements were made on a master cast poured from the impression and not on the impression itself.

Pant et al., (2008) investigated delayed pour and different storage temperatures of polyvinyl siloxane duplicating impression materials and found the dimensional change to be less than $2 \%$.

\subsubsection{TESTING OF ELASTOMERIC IMPRESSION MATERIALS}

Many scientific studies examined the influence of different variables, such as time, storage conditions and clinical technique, during impression making and casting of the impressions. However, these studies often introduced more than one possible variable and the true dimensional stability or accuracy of the impression material itself is not established, rather the accuracy of the procedure as a whole is assessed (Piwowarczyk et al., 2002).

\section{Methods}

There is no consistency in the literature in terms of methodology used for assessing dimensional stability of impression materials. Some publications report the use of a standard, but most publications describe some kind of clinically related technique incorporating unknown variables such as impression tray and casting materials. 
Measurements are made of the cast or of the impression itself. This lack of standardization makes direct comparisons among different studies difficult.

\section{Standards}

Several standards are developed for testing impression materials.

The American Dental Association (ADA) specification No. 19 introduced a standardized repeatable method in 1977 for preparing and evaluating test specimens of elastomeric material.

The British Standards Institution (BSI) employs a scribed block, which is used to form a disc of impression materials (British Standards Institution, 1987).

The International Organization for Standardization (ISO) is a worldwide federation of national standards bodies (ISO member bodies). They published a standard for testing and minimum requirements for elastomeric impression materials for dentistry (ISO 4823:2000). This standard describes in detail the manufacturing of the specimens using a custom-made test block with a special configuration of lines for determining detail reproduction and dimensional stability. The measurements are done on the impression material itself, eliminating any variable introduced by tray or casting procedures and materials.

There seems to be no consensus in the literature on the measuring device that should be used to evaluate the detail reproduction and dimensional stability of impression materials. Microscopes, travelling microscopes, calipers and scanners are used. Manual measuring devices are easy to use, however error due to operator fatigue must be accepted. It is also important to note that these standards date back 
to 1977, 1987 and 2000 and more modern measuring techniques are available now.

\subsection{CONCLUSION}

Impression making is a fundamental part of prosthodontic practice. A literature review indicated that few studies report on the influence of prolonged raised temperatures, as may be found during transport, on dimensional stability. Therefore the aim of this study is to investigate the effect of raised temperatures on the linear dimensional stability of elastomeric impression material.

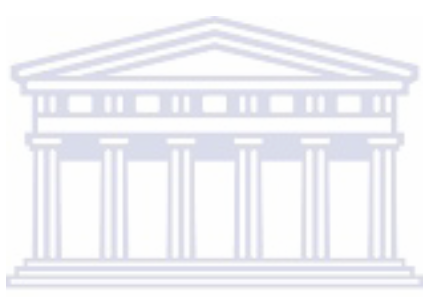




\section{CHAPTER 2: AIMS AND OBJECTIVES}

\subsection{AIM}

The aim of this in vitro study was to investigate the influence of temperature and time on the linear dimensional stability of a polyether and a silicone impression material.

\subsection{OBJECTIVES}

The objectives of this study were:

a. To establish if an increase in temperature influences the linear dimensional stability of a polyether impression material.

b. To establish if an increase in temperature influences the linear dimensional stability of a polyvinyl siloxane impression material.

c. To establish if time influences the linear dimensional stability of a polyether impression material.

d. To establish if time influences the linear dimensional stability of a polyvinyl siloxane impression material.

\subsection{NULL HYPOTHESES}

The null-hypotheses to be tested were:

a. Temperature has no influence on the linear dimensional stability of polyether or polyvinyl siloxane impression materials.

b. Time has no influence on the linear dimensional stability of polyether or polyvinyl siloxane impression materials. 


\section{CHAPTER 3: MATERIALS AND METHODS}

\subsection{INTRODUCTION}

This in vitro controlled comparative study assessed the influence of time and temperature on the linear dimensional stability of 2 different elastomeric impression materials.

The proposal was approved by the research and ethics committee of the University of the Western Cape. The study was conducted in the Department of Restorative Dentistry, Tygerberg Oral Health Center at the University of the Western Cape.

The fabrication of the specimens was done according to the specifications of the International Organization of Standardization (ISO) 4823:2000 for testing dental elastomeric impression materials. The measuring of the specimens was done digitally and not by means of a travelling microscope as is specified by ISO.

\subsection{METHODOLOGY}

\subsubsection{Stainless steel test block}

A stainless steel test block and ring was manufactured according to the specifications of ISO 4823:2000 for testing dental elastomeric impression materials. The surface of the test block was marked with 3 horizontal lines (no. 1, 2 and 3) intersected by 2 vertical lines (no. 4 and 5) (Fig 3.1).

Impressions of the test block's surface were made. The distance between lines 4 and 5 on the impressions' surface was digitally measured 3 times. (Figure 3.1) 
Only impressions that passed the ISO requirements for detail reproduction were used for dimensional stability measurements: a line reproduction was considered satisfactory if the required line 1,2 or 3 is continuous between the lines 4 and 5 (See test block in Figure 3.1). Impressions that failed the ISO requirements for detail reproduction were not used for the dimensional stability measurements.

Figure 3.1: Measuring the distance between line no. 4 and 5 along line 3 (ISO 4823).
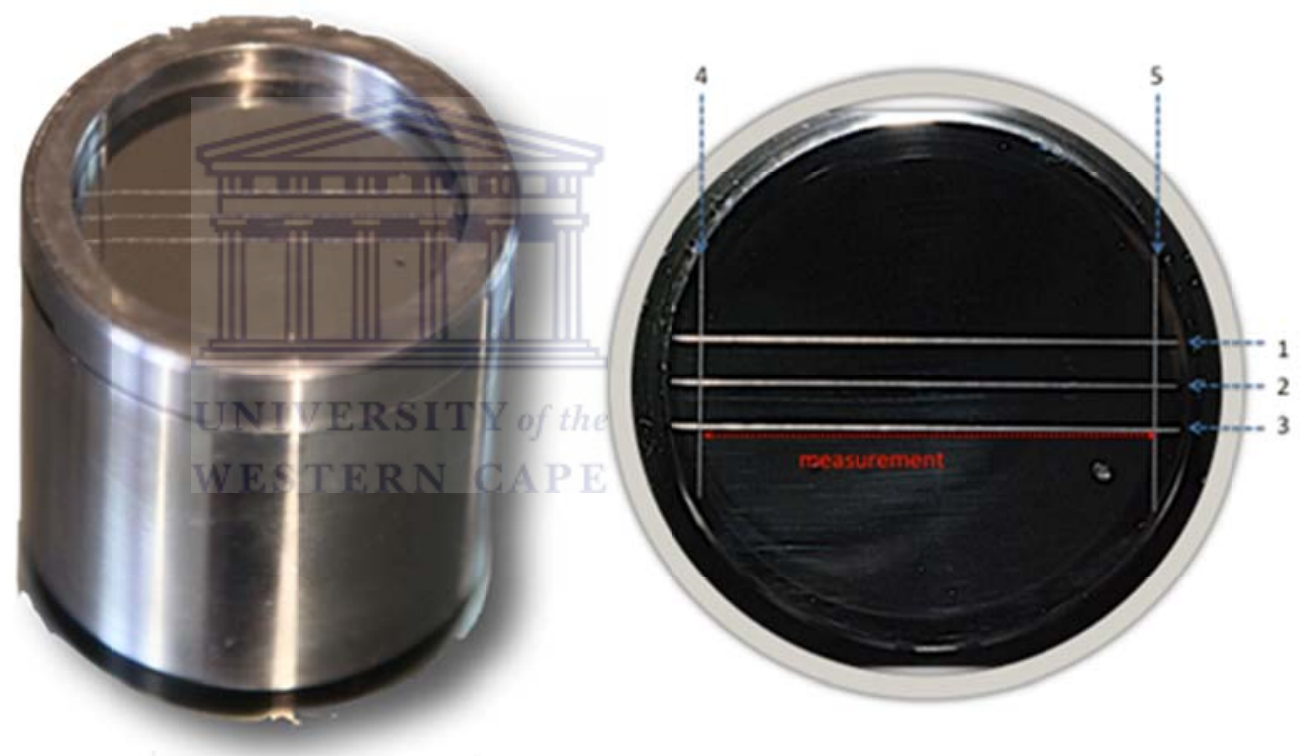

The average of the 3 measurements was used to calculate the percentage of dimensional change for each specimen to the nearest $0,000000001 \%$ using the equation:

$$
\% \mathrm{DC}=100[\mathrm{~L} 1-\mathrm{L} 2 / \mathrm{L} 1]
$$

with $\mathrm{L} 1=$ the distance measured on the test block and $\mathrm{L} 2=$ the distance measured on the specimen. According to ISO requirements, a specimen passes the dimensional stability test if the DC is not more than $1.5 \%$. 


\subsubsection{Impression Materials}

The impression materials used were a polyvinyl siloxane material (S) (Affinis ${ }^{\circledR}$ Precious regular body, Coltene/whaledent ${ }^{\circledR}$ ) and a polyether material (P) (Impregum $^{\mathrm{TM}}$ Penta $^{\mathrm{TM}}$, 3M ESPE). Both are type 2 elastomeric impression materials. See addendum 1 for material specifications.

The impression materials were handled according to manufacturers’ instructions.

\subsubsection{Groups}

Twelve groups of 10 specimens each were developed. The treatment of the specimens in the 12 groups was as follows:

- Group S*21*1 (control): silicone impression stored at room temperature $\left(21^{\circ} \mathrm{C} \pm 1\right)$, photographed after 30 minutes.

- Group S*21*2: silicone impression stored at room temperature, photographed after 8 hrs.

- Group S*21*3: silicone impression stored at room temperature, photographed after 14 days.

- Group S*66*1: silicone impression stored at $66^{\circ} \mathrm{C}$ for 8 hrs before photographed.

- Group $\mathrm{S}^{*} 66^{*} 2$ : silicone impression stored at $66^{\circ} \mathrm{C}$ for $8 \mathrm{hrs}$, cooled down to room temperature before photographed.

- Group S*66*3: silicone impression stored at $66^{\circ} \mathrm{C}$ for $8 \mathrm{hrs}$ and photographed at room temperature after 14 days.

- Group P*21*1 (control): polyether impression stored at room temperature, photographed after 30 minutes. 
- Group $\mathrm{P}^{*} 21 * 2$ : polyether impression stored at room temperature, photographed after 8 hrs.

- Group $\mathrm{P}^{*} 21 * 3$ : polyether impression stored at room temperature, photographed after 14 days.

- Group $\mathrm{P}^{*} 66^{*} 1$ : polyether impression stored at $66^{\circ} \mathrm{C}$ for 8 hrs before photographed.

- Group P*66*2: polyether impression stored at $66^{\circ} \mathrm{C}$ for $8 \mathrm{hrs}$, cooled down to room temperature before photographed.

- Group $\mathrm{P}^{*} 66^{*} 3$ : silicone impression stored at $66^{\circ} \mathrm{C}$ for $8 \mathrm{hrs}$ and photographed at room temperature after 14 days.

A summary of the identification of the groups and their treatment is given in Table 3.1.

In order to develop these 12 groups, a total of 40 specimens had to be made.

Specimens for groups $S * 21 * 1, S * 21 * 2$ and $S * 21 * 3$ were the same $(n=10)$

Specimens for groups $S * 66 * 1, S * 66 * 2$ and $S * 66 * 3$ were the same $(n=10)$

Specimens for groups $\mathrm{P} * 21 * 1, \mathrm{P} * 21 * 2$ and $\mathrm{P} * 21 * 3$ were the same $(\mathrm{n}=10)$

Specimens for groups $\mathrm{P} * 66 * 1, \mathrm{P} * 66 * 2$ and $\mathrm{P} * 66 * 3$ were the same $(\mathrm{n}=10)$.

\subsubsection{Specimen fabrication}

Before use, the test block and ring were ultrasonically cleaned and placed in an oven, set at $35 \pm 1^{\circ} \mathrm{C}$ for at least 15 min for conditioning. All the impressions were made using prepackaged cartridges of polyether and polyvinyl siloxane with a micro plastic dispenser MKII (Coltene/whaledent ${ }^{\circledR}$ ) and the Pentamix 2 electric mixing unit (3M ESPE) respectively. The ring was positioned over the block and the cavity that is formed in this way was filled with impression material. A 
polyethylene-covered glass plate was placed over the ring and pressed down until excess material was expelled. A thin film of silicone grease was sprayed over the plate to help secure the polyethylene sheet to the plate. At 60 s after completion of the mix, this specimen-forming assembly was placed in a water bath at $37^{\circ} \mathrm{C}$ for the minimum time recommended by the manufacturer's instructions for leaving the impression in the mouth (Affinis: 3:00 min \& Impregum: 3:15 min). Consequently, the impression material specimen in the ring mould was separated from the test block. The specimen surface was flushed with distilled water and dried using a gentle stream of clean air. The specimens were treated according to the regimens indicated for the 12 groups (Table 3.1).

Table 3.1: This table shows for each group the exposure to temperature, time interval between impression taking and reading and conditions at which readings are made. $\mathrm{P}=$ polyether, $\mathrm{S}$ = silicone.

\begin{tabular}{|c|c|c|c|}
\hline Group & Temperature $\left({ }^{\circ} \mathrm{C}\right)$ & Time & Conditions \\
\hline $\mathrm{S} * 21 * 1 \& \mathrm{P} * 21 * 1$ & 21 & $30 \mathrm{~min}$ & 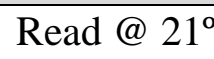 \\
\hline $\mathrm{S} * 21 * 2 \& \mathrm{P} * 21 * 2$ & 21 & 8hrs & 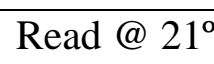 \\
\hline $\mathrm{S} * 21 * 3 \& \mathrm{P} * 21 * 3$ & 21 & 14days & 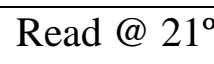 \\
\hline $\mathrm{S} * 66 * 1 \& \mathrm{P} * 66 * 1$ & 66 & $8 \mathrm{hrs}$ & Read@66º \\
\hline $\mathrm{S} * 66 * 2$ \& $\mathrm{P} * 66 * 2$ & $\begin{array}{l}66 \\
21\end{array}$ & $\begin{array}{l}\text { 8hrs } \\
\text { 8hrs }\end{array}$ & Read @ 21 \\
\hline $\mathrm{S} * 66 * 3 \& \mathrm{P} * 66 * 3$ & $\begin{array}{l}66 \\
21\end{array}$ & $\begin{array}{l}\text { 8hrs } \\
\text { 14days }\end{array}$ & Read @ 21 \\
\hline
\end{tabular}

\subsubsection{Digital Image Analysis}

Images of the specimens were taken at the time/temperature conditions as specified 
in the last two columns of table 3.1. The specimens, together with a ruler $(0.5 \mathrm{~mm}$ scale) were photographed with a SLR digital camera (Nikon D80, macro lens) using a standardized technique: sensor, specimen and ruler were all mounted parallel to each other (Figures 3.2 and 3.3)

Figure 3.2: Mounting of the camera and specimen for the digital imaging.

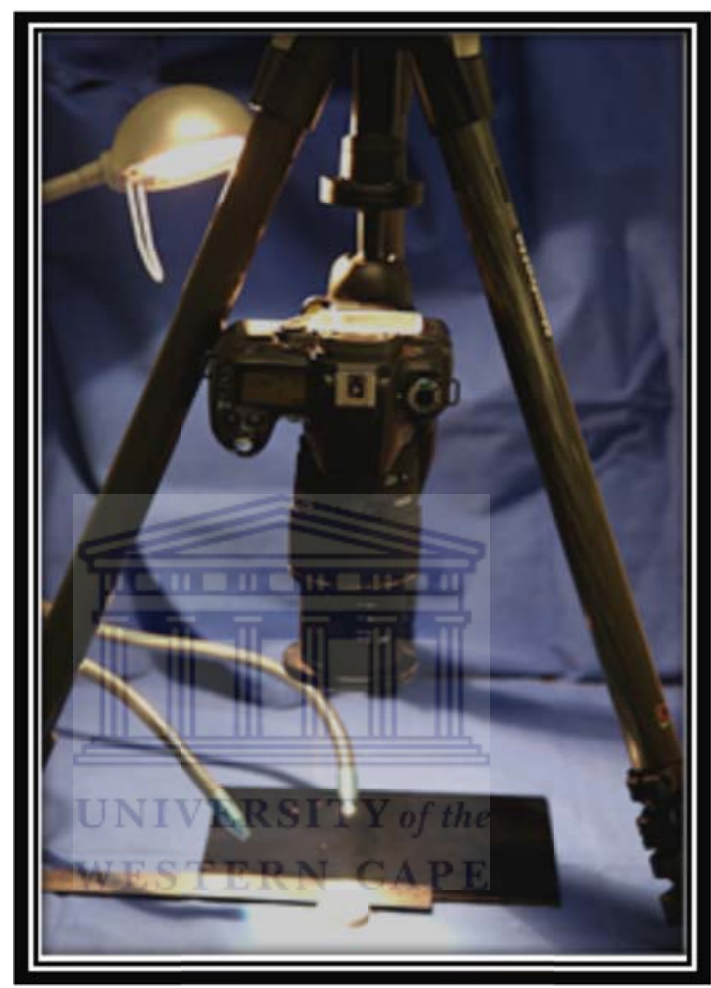

Figure 3.3: Image of a specimen with calibrating ruler.

The dimension of the images was 3872 x 2592 pixels.

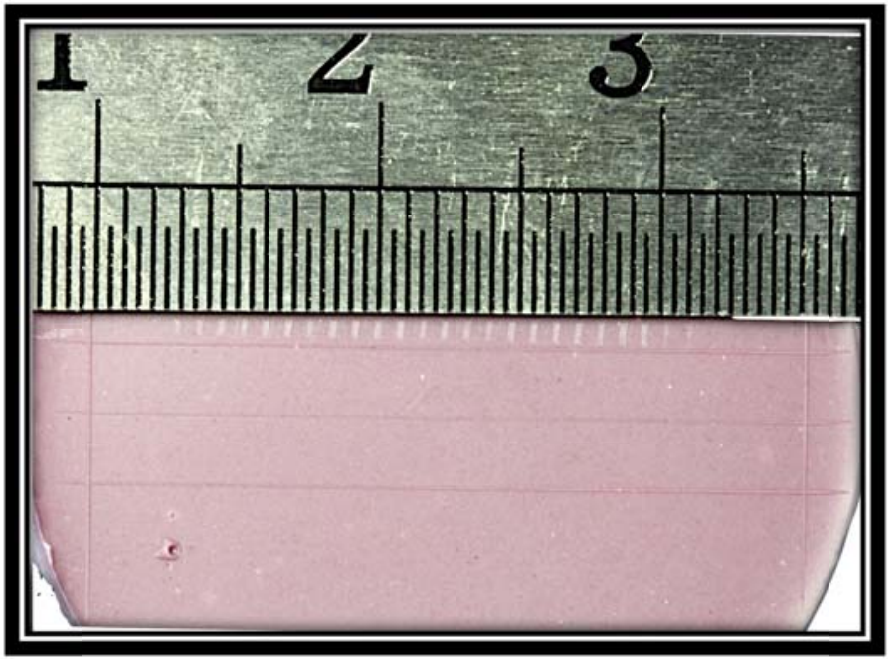


Width: 3872 pixels

Height: 2592 pixels

The software used for measuring the images was AnalyzingDigitalImages, version 11, August 2008. This software was developed by the Museum of Science, Boston, and may be freely downloaded and used for educational purposes (http://mvh.sr.unh.edu). It allows scaling, calibration and analysis of digital images up to a magnification of 9 . The distances were measured up to $0.00001 \mathrm{~mm}$ accuracy $(0.01 \mu \mathrm{m})$.

\subsection{DATA ANALYSIS}

For the descriptive statistics Microsoft Excel 2010 was used. VEPAC module of Statistica 10 was used for the statistical analysis. Three factors that were considered: a) material type (P or S); b) temperature (21 or 66$)$; and time point for measurement (1, 2 or 3$)$. It was this factor that caused the repeated measurement of the same sample, resulting in repeated measures analysis of variance (ANOVA). Interactions between all variables were also analyzed. To analyze exactly where the differences lay, a Fisher LSD correction was applied to correct for multiple pairwise comparisons. The normal probability plot of the mixed model ANOVA was checked for normality and judged to be not a problem (results not shown).

Twenty comparisons were selected from the multiple pairwise comparisons (addendum 5) to establish the effect of time and temperature on the dimensional stability of the 2 impression materials: 
To establish the effect of:

1. different materials on the DS, the following groups were compared:

$\begin{array}{lll}\mathrm{S} * 21 * 1 & \& & \mathrm{P} * 21 * 1 \\ \mathrm{~S} * 21 * 2 & \& & \mathrm{P} * 21 * 2 \\ \mathrm{~S} * 21 * 3 & \& & \mathrm{P} * 21 * 3 \\ \mathrm{~S} * 66 * 1 & \& & \mathrm{P} * 66 * 1 \\ \mathrm{~S} * 66 * 2 & \& & \mathrm{P} * 66 * 2 \\ \mathrm{~S} * 66 * 3 & \& & \mathrm{P} * 66 * 3\end{array}$

2. time on the DS the following groups were compared:

$\begin{array}{lll}\mathrm{S} * 21 * 1 & \& & \mathrm{~S} * 21 * 2 \\ \mathrm{~S} * 21 * 2 & \& & \mathrm{~S} * 21 * 3 \\ \mathrm{~S} * 21 * 1 & \& & \mathrm{~S} * 21 * 3 \\ \mathrm{~S} * 66 * 2 & \& & \mathrm{~S} * 66 * 3 \\ \mathrm{P} * 21 * 1 & \& & \mathrm{P} * 21 * 2 \\ \mathrm{P} * 21 * 2 & \& & \mathrm{P} * 21 * 3 \\ \mathrm{P} * 21 * 1 & \& & \mathrm{P} * 21 * 3 \\ \mathrm{P} * 66 * 2 & \& & \mathrm{P} * 66 * 3\end{array}$

3. exposure to temperature on the DS the following groups were compared:

$\begin{array}{lll}\mathrm{S} * 21 * 2 & \& & \mathrm{~S} * 66 * 2 \\ \mathrm{~S} * 21 * 3 & \& & \mathrm{~S} * 66 * 3 \\ \mathrm{P} * 21 * 2 & \& & \mathrm{P} * 66 * 2 \\ \mathrm{P} * 21 * 3 & \& & \mathrm{P} * 66 * 3\end{array}$

4. temperature of the specimen at the time of reading on the DS the following groups were compared:

$\begin{array}{lll}\mathrm{S} * 66 * 1 & \& & \mathrm{~S} * 66 * 2 \\ \mathrm{P} * 66 * 1 & \& & \mathrm{P} * 66 * 2\end{array}$




\section{CHAPTER 4: RESULTS}

\subsection{INTRODUCTION}

All specimens passed the ISO requirements for detail reproduction. Therefore, no specimens had to be replaced.

The complete data set consisting of the raw data, percentage dimensional change (\%DC) for all groups and multiple comparisons are shown in Addendum 4, 5 and 6.

\subsection{DESCRIPTIVE STATISTICS}

The descriptive statistics for all the groups of both impression materials are represented in Tables 4.1 and 4.2. Note that a negative \%DC implies that the linear dimension of the specimen is larger than that of the test block and that a positive \%DC implies that the specimen has linear dimension smaller than that of the test block. For the determination of the minimum \%DC, the value closest to zero \%DC is chosen and for the maximum \%DC the value furthest away from zero \%DC is chosen. 
Table 4.1: Summary of the descriptive statistics (\%DC) for the polyether impression material $(P)$. (St Dev = standard deviation)

\begin{tabular}{|c|c|c|c|c|c|c|}
\hline Group & $P * 21 * 1$ & $P * 21 * 2$ & P*21*3 & $P * 66 * 1$ & $P^{*} 66 * 2$ & P*66*3 \\
\hline Mean & 0.120188 & 0.364424 & -0.038932 & 0.202031 & 0.306417 & -0.272346 \\
\hline Median & 0,114914 & 0.389232 & 0.039426 & 0.229160 & 0.313170 & 0.259654 \\
\hline Minimum & 0.014910 & 0.230039 & 0.004073 & 0.084989 & 0.206713 & -0.092288 \\
\hline Maximum & 0.237458 & 0.432349 & -0.217358 & 0.607219 & 0.417062 & -0.447477 \\
\hline St Dev & 0.059507 & 0.064329 & 0.091504 & 0.240434 & 0.072987 & 0.121282 \\
\hline
\end{tabular}

The lowest mean \%DC for the polyether material was found for the group that was left for 2 weeks at room temperature before measurements were made (group $\mathrm{P}^{*} 21 * 3$ with a mean $\% \mathrm{DC}=-0.038932)$. The highest mean \%DC was found for group that was kept at $21^{\circ} \mathrm{C}$ for 8 hours $(\mathrm{P} * 21 * 2, \% \mathrm{DC}=0.364424)$.

Table 4.2: Summary of the descriptive statistics (\%DC) for the silicone impression material (S). (St Dev = standard deviation)

\begin{tabular}{|c|c|c|c|c|c|c|}
\hline Group & S*21*1 & S*21*2 & S*21*3 & S*66*1 & S*66*2 & S*66*3 \\
\hline Mean & -0.086977 & 0.237352 & 0.005887 & -0.094716 & 0.297070 & -0.092751 \\
\hline Median & 0.115694 & 0.237160 & 0.026117 & 0.098331 & 0.273043 & 0.084731 \\
\hline Minimum & 0.037846 & 0.181363 & 0.011346 & 0.053560 & 0.190540 & -0.036775 \\
\hline Maximum & -0.215824 & 0.300456 & -0.094338 & -0.151028 & 0.426583 & -0.167174 \\
\hline St Dev & 0.101006 & 0.036468 & 0.051674 & 0.058153 & 0.085290 & 0.043492 \\
\hline
\end{tabular}


The lowest mean \%DC for the silicone impression material was found for the group that was left for 2 weeks at room temperature before measurements were made (group $S * 21 * 3$ and \%DC 0.005887). This was the group with \%DC lower than the lowest \%DC of the pmaterial. The highest mean \%DC was found for group that was heated to $66^{\circ} \mathrm{C}$ for $8 \mathrm{hrs}$ and cooled off to room temperature for another 8 hrs (group $\mathrm{S}^{*} 66^{*} 2$ with a \%DC of 0.29707).

\subsection{STATISTICAL ANALYSIS}

Results from the fixed effect test for \%DC indicated the presence of statistically significant differences (Table 4.3)

Table 4.3: Fixed effect test for \%DC

\begin{tabular}{|l|c|c|c|c|c|}
\hline \multicolumn{1}{|c|}{ Effect } & $\begin{array}{c}\text { Num. } \\
\text { DF }\end{array}$ & Den. DF & F & p & \\
\hline Material & 1 & 36 & 11.54 & 0.00 & $<0.01$ \\
\hline Temperature & 1 & 36 & 4.38 & 0.04 & \\
\hline Time & 2 & 72 & 188.34 & 0.00 & $<0.01$ \\
\hline Material*Temperature & 1 & 36 & 1.77 & 0.19 & \\
\hline Material*Time & 2 & 72 & 37.52 & 0.00 & $<0.01$ \\
\hline Temperature*Time & 2 & 72 & 13.27 & 0.00 & $<0.01$ \\
\hline Material*Temperature*Time & 2 & 72 & 4.41 & 0.02 & \\
\hline
\end{tabular}


Figure 4.4: Effect of different materials on the \%DC.

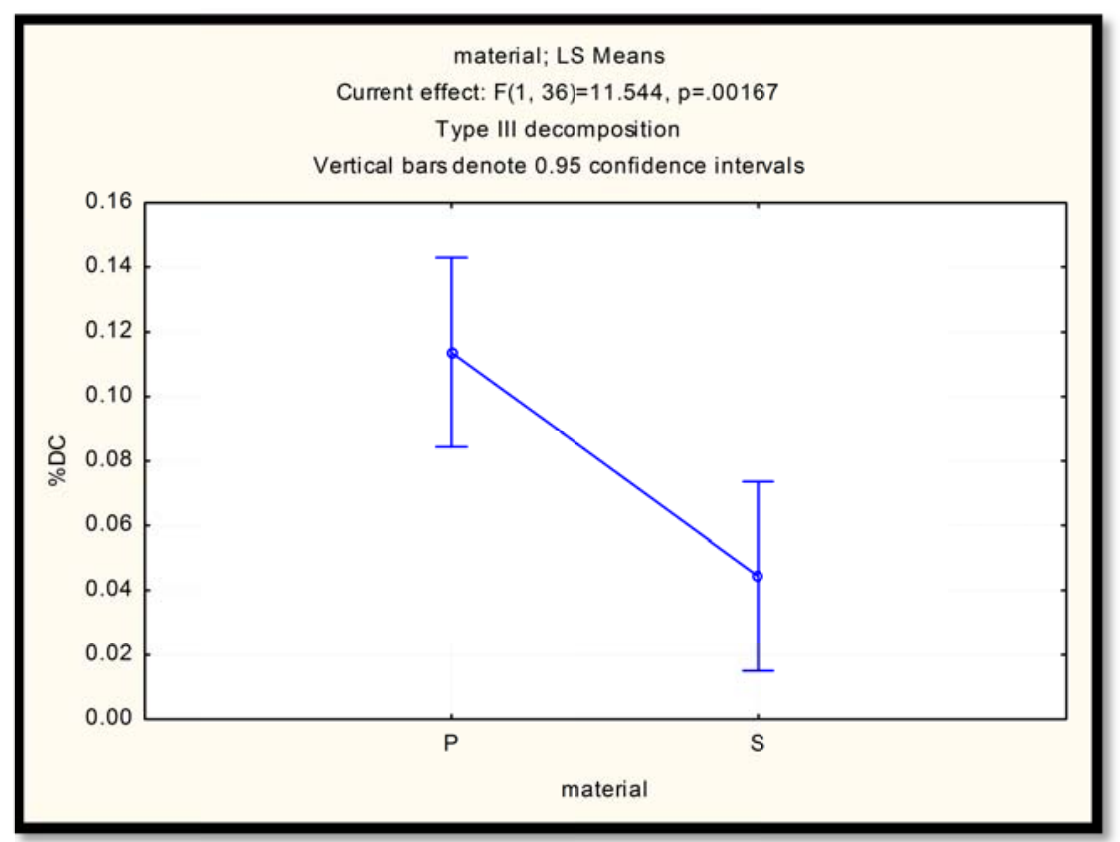

Figure 4.4 demonstrates the effect of different materials on the \%DC. To establish the effect of material on linear dimensional stability, pairs of groups subjected to the same time/temperature regimen for each material were compared with each other (Table 4.4). There was a significant difference in \%DC for all the pairs, except between the groups left for 2 weeks at room temperature $(\mathrm{S} * 21 * 3 \& \mathrm{P} * 21 * 3)$ and between the groups exposed to $66^{\circ} \mathrm{C}$, cooled off and measured after 8hrs (S*66*2 \& P*66*2).

Table 4.4: This table shows pairs of groups and p-values to demonstrate the effect of different materials on the \%DC. Red p-value represents significant difference.

\begin{tabular}{|c|c|c|}
\hline \multicolumn{2}{|c|}{ Groups } & P-value \\
\hline $\mathrm{S} * 21 * 1$ & $\mathrm{P} * 21 * 1$ & 0.000016 \\
\hline $\mathrm{S} * 21 * 2$ & $\mathrm{P} * 21 * 2$ & 0.0059650 \\
\hline $\mathrm{S} * 21 * 3$ & $\mathrm{P} * 21 * 3$ & 0.320918 \\
\hline $\mathrm{S} * 66 * 1$ & $\mathrm{P} * 66 * 1$ & 0.000000 \\
\hline $\mathrm{S} * 66 * 2$ & $\mathrm{P} * 66 * 2$ & 0.835480 \\
\hline $\mathrm{S} * 66 * 3$ & $\mathrm{P} * 66 * 3$ & 0.000149 \\
\hline
\end{tabular}


Figure 4.5: The effect of time on the mean $\% D C .1$ after 30 min of making the impression; 2 = after 8hrs; $3=$ after 14 days.

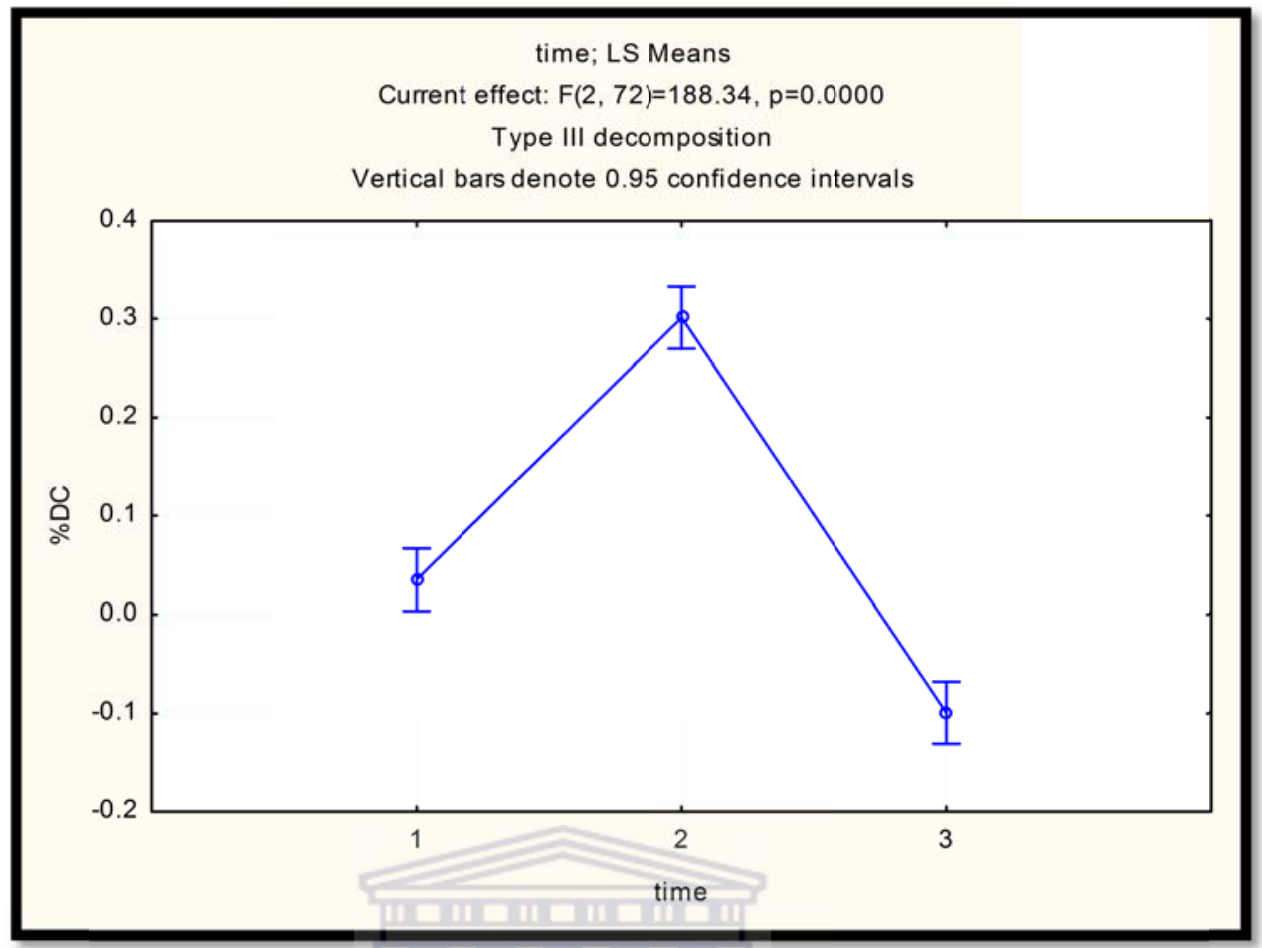

Figure 4.5 demonstrates the effect of time on the \%DC. To establish the effect of time on the linear dimensional stability the groups in table 4.5 were compared. All pairs showed a significant difference in \%DC.

Table 4.5:

This table shows the pairs of groups and p-values to demonstrate the effect of time on the \%DC. Red p-values represent significant differences.

\begin{tabular}{|c|c|c|}
\hline \multicolumn{2}{|c|}{ Groups } & P-value \\
\hline $\mathrm{S} * 21 * 1$ & $\mathrm{~S} * 21 * 2$ & 0.000000 \\
\hline $\mathrm{S} * 21 * 2$ & $\mathrm{~S} * 21 * 3$ & 0.000001 \\
\hline $\mathrm{S} * 21 * 1$ & $\mathrm{~S} * 21 * 3$ & 0.030365 \\
\hline $\mathrm{S} * 66 * 2$ & $\mathrm{~S} * 66 * 3$ & 0.000000 \\
\hline $\mathrm{P} * 21 * 1$ & $\mathrm{P} * 21 * 2$ & 0.000000 \\
\hline $\mathrm{P} * 21 * 2$ & $\mathrm{P} * 21 * 3$ & 0.000000 \\
\hline $\mathrm{P} * 21 * 1$ & $\mathrm{P} * 21 * 3$ & 0.000316 \\
\hline $\mathrm{P} * 66 * 2$ & $\mathrm{P} * 66 * 3$ & 0.000000 \\
\hline
\end{tabular}


Figure 4.6: The effect of temperature on the \%DC.

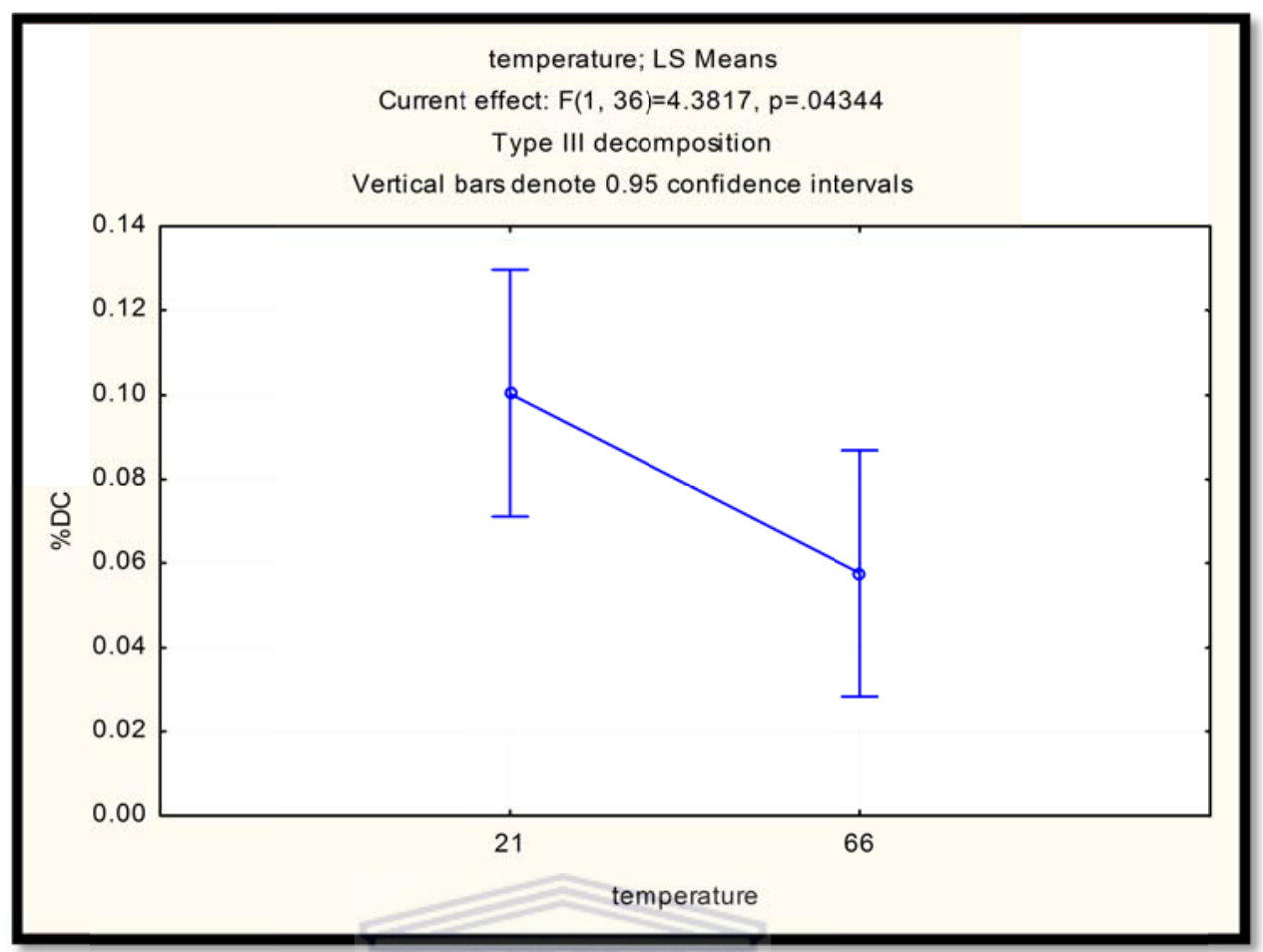

Figure 4.6 demonstrates the effect of only temperature on the \%DC. To establish the effect of exposure to temperature on dimensional stability, the groups in table 4.6 were compared.

Table 4.6

This table shows the pairs of groups and p-values to demonstrate the effect of exposure to temperature on the \%DC.

Red p-values represent significant differences.

\begin{tabular}{|l|l|c|}
\hline \multicolumn{2}{|c|}{ Groups } & P-value \\
\hline $\mathrm{S} * 21 * 2$ & $\mathrm{~S} * 66 * 2$ & 0.187143 \\
\hline $\mathrm{S} * 21 * 3$ & $\mathrm{~S} * 66 * 3$ & 0.031040 \\
\hline $\mathrm{P} * 21 * 2$ & $\mathrm{P} * 66 * 2$ & 0.199941 \\
\hline $\mathrm{P} * 21 * 3$ & $\mathrm{P} * 66 * 3$ & 0.000002 \\
\hline
\end{tabular}

For silicone, the specimens that were kept at room temperature for 14 days $\left(\mathrm{S}^{*} 21 * 3\right)$ and the specimens that were exposed to $66^{\circ} \mathrm{C}$ for $8 \mathrm{hrs}$ and then left at room temperature for 14 
days ( $\mathrm{S} * 66 * 3)$, differed significantly with a p-value of 0.031040 .

Likewise, for polyether, the specimens that were kept at room temperature for 14 days $\left(\mathrm{P}^{*} 21^{*}\right)$ and the specimens that were exposed to $66^{\circ} \mathrm{C}$ for $8 \mathrm{hrs}$ and then kept at room temperature for a further 14 days $\left(\mathrm{P}^{*} 66 * 3\right)$, differed significantly with a p-value of 0.000002 .

Figure 4.7: The effect of temperature and time on the mean \%DC.

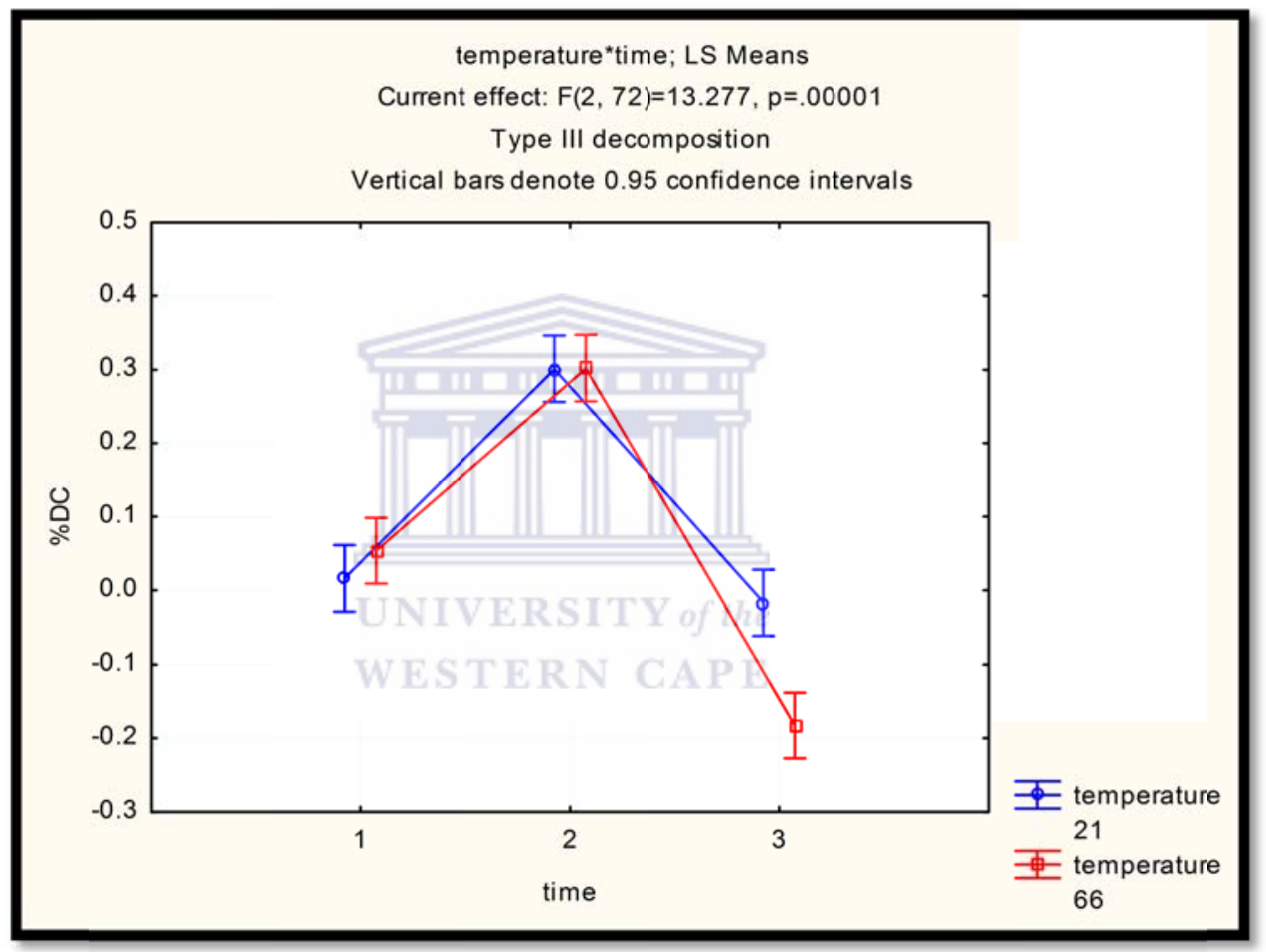

Figure 4.7 demonstrates the effect of temperature and time on the \%DC. As can be seen from table 4.7 , cooling off from $66^{\circ} \mathrm{C}$ to room temperature (S*66*1 \& $\mathrm{S} * 66^{*} 2$ ) caused a difference in \%DC ( $\mathrm{p}=0.000000)$ for the silicone impression materiall. There was also a significant difference when polyether was cooling off from $66^{\circ} \mathrm{C}$ to room temperature $(\mathrm{P} * 66 * 1$ \& $\mathrm{P} * 66 * 2)$ with a p-value of 0.015362 . 


\section{Table 4.7}

This table shows the pairs of groups and p-values

to demonstrate the effect of temperature of the specimens at the time of reading on the $\% D C$.

Shaded p-values represent significant differences

\begin{tabular}{|c|c|c|}
\hline \multicolumn{2}{|c|}{ Groups } & P-value \\
\hline $\mathrm{S} * 66 * 1$ & $\mathrm{~S} * 66 * 2$ & 0.000000 \\
\hline $\mathrm{P} * 66 * 1$ & $\mathrm{P} * 66 * 2$ & 0.015362 \\
\hline
\end{tabular}

Figure 4.8 summarizes the effects of all the variables on the mean \%DC. It is important to keep in mind that times 1, 2 and 3 for the blue and the red line are not the same (see also table 3.1). For the blue line, time $\mathbf{1}=30$ minutes and for the red line it is 8hours. Time 2 for the blue line is 8 hours and for the red line it is $16 \mathrm{hrs}\left(8 \mathrm{hrs}\right.$ at $66^{\circ} \mathrm{C}$ and an additional 8hrs for returning to $21^{\circ} \mathrm{C}$ ). The same letters indicate no statistical difference between groups, whereas different letters indicate statistical difference between groups.

Figure 4.8. Mean \%DC for time, temperature and materials

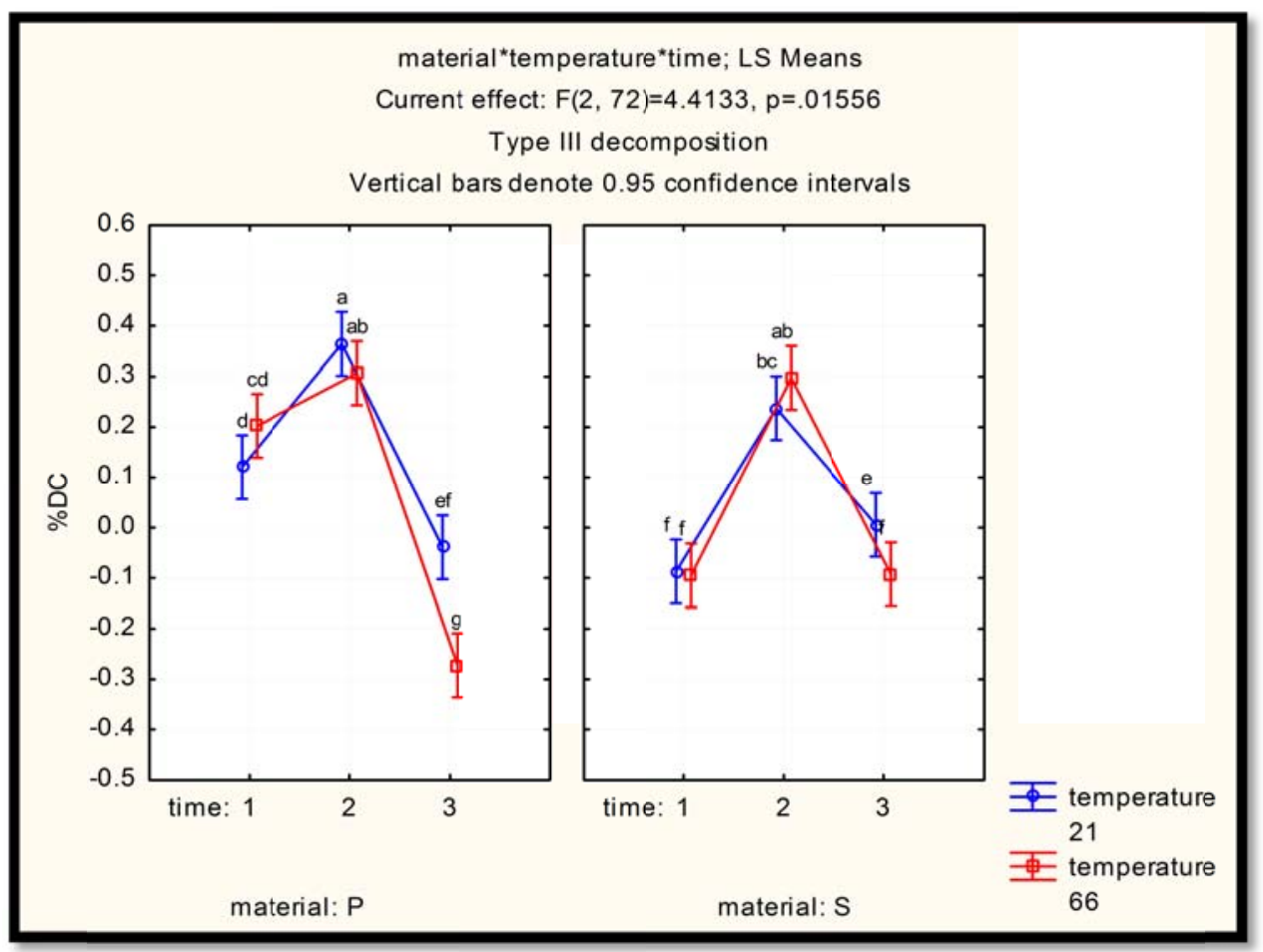




\section{CHAPTER 5: DISCUSSION AND CONCLUSIONS}

\subsection{DISCUSSION OF THE RESULTS}

This study investigated the influence of temperature and time on the linear dimensional stability of 2 types of elastomeric impression materials. The null-hypotheses stating that temperature or time have no influence on the linear dimensional stability of elastomeric impression materials, is rejected.

Even though statistical differences were found, it is important to remember that all the groups for both materials showed a mean dimensional change (DC) considerably lower than the recommended DC of not more than $1.5 \%$.

For the explanation of the statistical results in the following discussion, it is helpful to refer to figure 4.8 .

The linear dimensional stability of both materials is influenced by temperature, albeit in different ways.

Given enough time to recover (14 days at room temperature) after an 8hr period of exposure to an elevated temperature, the silicone impression material returns to its original dimension. This is evidenced by no statistical difference between groups $\mathrm{S} * 66 * 1$ \& $S * 66 * 3$ or $S * 21 * 1 \& S * 66 * 1$. However, keeping the silicone impression material at room temperature for 14 days resulted in the highest dimensional accuracy. This accuracy was even higher than at 30 minutes after impression making. This difference was significant. 
However, for polyether impression material a 14 day recovery at room temperature (after an extended period of exposure to an elevated temperature) resulted in an expansion. This expansion was significant.

For silicone specimens, the group that was left for 2 weeks at room temperature (S*21*3) was compared with the group that was exposed to $66^{\circ} \mathrm{C}$ for $8 \mathrm{hrs}$ and then left at room temperature for another 2 weeks $\left(S^{*} 66 * 3\right)$, there was a significant difference with a pvalue of 0.031040 .

For polyether, the group that was left for 14 days at room temperature $(\mathrm{P} * 21 * 3)$ was compared with the group that was exposed to $66^{\circ} \mathrm{C}$ for $8 \mathrm{hrs}$ and then left at room temperature for another 2 weeks $\left(\mathrm{P}^{*} 66 * 3\right)$, there was a significant difference with a pvalue of 0.000002 . The largest difference in \%DC happened between the abovementioned groups. Lacy et al. (1981) and Williams et al. (1984) reported that polyether material seem to be affected by imbibition resulting in expansion. The results of my research seem to confirm this. In addition, the group exposed to $66^{\circ} \mathrm{C}$ showed more expansion than the $21^{\circ} \mathrm{C}$ group. However, this effect was only apparent at 14 days. At 30 minutes and 8 hrs the linear dimensions were actually smaller. The smaller dimension may be due to polymerization shrinkage (Rubel, 2007). Modern materials still seem to be affected by dimensional fluctuations attributed to polymerization shrinkage and imbibition as previously described by Lacy et al. (1981), Williams et al. (1984) and Rubel (2007).

Exposing impression materials to an elevated temperature introduces another variable: time. Interpreting the results, these 2 variables must be analyzed together. For that reason a group of specimens not exposed to a higher temperature, but exposed to the same timeline acted as a control. For example, polyether that was kept at room temperature for 14 days 
$(\mathrm{P} * 21 * 3)$, was closer to $0 \% \mathrm{DC}$ than any other time or temperature group. Polyether that was heated to $66^{\circ} \mathrm{C}$ and allowed to cool off and recover for 14 days ( $\left.\mathrm{P} * 66^{*} 3\right)$, expanded significantly. Therefore, it is concluded that it is the temperature and not the time that caused the difference.

To establish the effect of material on dimensional stability, pairs of groups subjected to the same time/temperature regimen for each material were compared with each other (Table 4.4). The 2 materials behaved differently for all time/temperature scenarios, except for 2 pairwise comparisons: Firstly, when left for 2 weeks at room temperature, there was no significant difference in \%DC between the two materials. The mean \%DC was lower for the silicone material compared to the polyether. And secondly, there was also no difference between the two materials measured after 8 hours when previously exposed to $66^{\circ} \mathrm{C}$. This may be due to the polyether material absorbing moisture during storage time, as previously suggested by Lacy et al (1981) and Williams et al. (1984). Modern materials still seem to be affected by the imbibition described by these authors.

When specimens were kept at room temperature, there was a significant difference between the \%DC when measured at 30 minutes and 8 hours after impression making, and also between the \%DC measured at 8 hours and 14 days. There was also a significant difference between the 30 minute and 14 days readings, except for the silicone group that was not heated (Table 4.4). This phenomenon compensated for the initial expansion of the material in the first 30 minutes, and resulted in the most dimensionally accurate group of the complete study $(\mathrm{S} * 21 * 3)$. After 8 hrs, for both materials and temperatures, the \%DC was the highest (i.e. $\mathrm{S} * 21 * 2 ; \mathrm{S} * 66 * 2 ; \mathrm{P} * 21 * 2 ; \mathrm{P} * 66 * 2$ were the most dimensionally inaccurate). 
Exposing both materials to $66^{\circ} \mathrm{C}$ for 8 hours compared to keeping them at $21^{\circ} \mathrm{C}$ did not have a significant effect on the \%DC (Table 4.6).

However, the temperature of the specimens at the time of recording had a significant effect on the \%DC for silicone, but not for the polyether. This was previously described by De Araujo and Jorgensen (1986), who recommended that impressions should be warmed to body temperature before pouring. Therefore, it is recommended that, in hot climates, silicone impressions are allowed to return to room temperature when they are delivered to the laboratory.

To investigate the influence of temperature, the specimens were subjected to a temperature for $66^{\circ} \mathrm{C}$ for the duration of 8 hours. This temperature was chosen because it was recorded as a temperature that occurred in delivery vehicles during American summers when the outside temperature was $32^{\circ} \mathrm{C}$. During South African summers, these temperatures are easily reached. The time interval of 8 hours was an arbitrary time period for both the $21^{\circ} \mathrm{C}$ and $66^{\circ} \mathrm{C}$ groups of specimens to allow comparison between the 2 groups and it was thought that 8 hours might be a realistic time lapse between impression making in the surgery and fabrication of the cast in the laboratory.

Piwowarczyk et al. (2002) reported that detail reproduction and dimensional stability of impression materials can only be determined when any other variable is excluded from the methodology. Following the ISO methods, in this study the specimens themselves were measured, and not reproductions by means of casts. Also, no support by means of impression tray material was necessary. This eliminated any variable introduced by casting procedures and additional materials used in the process such as dental stones, tray and adhesive materials. Therefore, dimensional changes in this study are exclusively attributed to the impression material. Unfortunately, most scientific studies investigating dimensional 
stability of elastomeric impression materials have included these variables, obscuring the real property of the material and making comparison among studies difficult. The accuracy of elastomeric impression materials is higher than that of gypsum casts (Donovan and Chee, 2004). Therefore, measuring casts in order to determine the accuracy of impression materials is not indicated.

ISO recommends the use of a travelling microscope for measuring the distance on the specimens. Unfortunately, no travelling microscope was available to the researchers. Therefore, it was decided to use a novel technique of measuring dimensions from digital images from the specimens and not from the specimens themselves. This had the benefit of minimizing temperature loss from the moment of removal from the incubator until the image was taken: it was assumed that making a photograph of a specimen was faster than mounting the specimen on a travelling microscope and manipulating the apparatus to do 3 readings. By the time the $3^{\text {rd }}$ reading is done using a microscope, the specimen must have cooled off. A second benefit was that the specimens are digitally stored and can be measured and re-measured at any given time. It is not known how the results using this digital technique would compare to results using the conventional technique of a travelling microscope.

Since no undercuts were incorporated into the ISO specified mold, no elastic recovery could have played a role in the fluctuations of the \%DC. The influence of elastic recovery on dimensional stability could be investigated further. 


\subsection{LIMITATIONS}

Dimensional stability is only one physical property that contributes to the performance of an impression material. In addition, the results of in vitro studies do not necessarily predict clinical performance. However, impression materials fall in the category of dental materials where laboratory tests have some level of correlation with clinical performance since impression materials function for a short period of time and predominantly extraorally (Kelly, 2006).

This study is limited because only 1 elevated temperature, $66^{\circ} \mathrm{C}$, was chosen to investigate the dimensional stability of elastomer impression materials.

Another limitation is the use of one brand for each type of elastomer. Extrapolation of the results obtained with these products to other brands of related materials must be done with care. Minor variations in chemical composition may influence results.

\subsection{CONCLUSIONS AND RECOMMENDATIONS}

Within the limitations of this in vitro study, the following conclusions can be made in terms of dimensional stability:

1. Silicone impression material recovers after an extended period at elevated temperature.

2. Polyether impression material did not recover after an extended period at elevated temperature. It showed an expansion, after an initial contraction.

3. For both impression materials, storing at room temperature for 2 weeks resulted in the highest dimensional accuracy. 
4. Even though statistical differences were found, both materials are within ISOspecification for dimensional stability, even when heated for a prolonged period.

It is recommended that silicone and polyether impression material be kept at room temperature if they cannot be poured within 30 minutes. This is especially important for polyether impression material, since it does not recover to "pre-heating" dimensional accuracy.

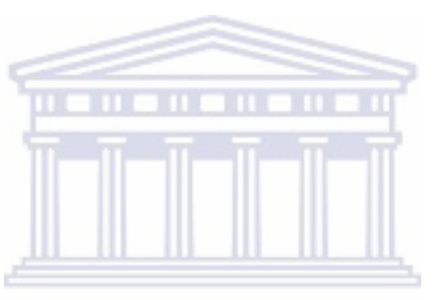

UNIVERSITY of the 


\section{REFERENCES}

American National Standard /American Dental Association. Specification number 19 for non-aqueous, elastomeric dental impressions. Journal of American Dental Assocciation.1977; 94:733-41; addendum 1999; 105: 686.

AnalyzingDigitalImages. http://mvh.sr.unh.edu/software. Accessed and downloaded 1 February 2011.

Anusavice KJ. 2003. Philips’ Science of Dental Materials (ed 11). Philadelphia, Saunders, p. 12, 205-231.

British Standards Institution (BS 4269: Part 1). 1987. Dental elastic impression materials Part 1. Specification for elastomeric impression materials.

Chen ST, Liang WM and Chen FN. Factors affecting the accuracy of elastomeric impression materials. Journal of Dentistry 2004; 32: 603-609.

Corso M, Abanomy A, Canzio J, Zurakowski D and Morgano S. The effect of temperature changes on the dimensional stability of polyvinyl siloxane and polyether impression materials. Journal of Prosthetic Dentistry 1998; 79: 626- 631.

Craig RG, Powers JM and Wataha JC. 2004. Dental Materials, Properties and Manipulation, (ed 8) St Louis, Mosby. 
De Araujo PA and Jorgensen KD. Improved accuracy by reheating addition reaction silicone impressions. Journal of Prosthetic Dentistry 1986; 55:11-2.

Donovan TE and Chee WWL. A Review of Contemporary Impression Materials and Techniques. Dental Clinics of North America 2004; 48: 445- 470.

Glossary of prosthodontic terms [editorial]. Journal of Prosthetic Dentistry 2005; 94: 1092.

Hamalian TA, Nasr E and Chidiac JJ. Impression Materials in Fixed Prosthodontics: Influence of Choice on Clinical Procedure. Journal of Prosthodontics 2011. 20 135-160.

ISO 4823 for elastomeric Impression Materials. International Organization for Standardization (ISO) Technical Committee: Tc 106/Sc 2; 2000. www.iso.org (purchased on 2 Dec 2010).

Johnson GH and Craig RG. Accuracy of addition silicones as a function of technique. Journal of Prosthetic Dentistry 1986; 55: 197-203.

Kelly JR. Evidence-based decision making: Guide to reading the dental materials literature. Journal of Prosthetic Dentistry 2006; 95: 152-160.

Lacy AM, Bellman T, Fukui H, Bellman T, and Jendrensen MD. Time-dependent accuracy of elastomer impression materials. Part 1: Condensation silicones. Journal of Prosthetic Dentistry 1981; 45: 209-215. 
Marcinak CF and Draughn RA. Linear dimensional change in addition silicone impression material. Journal of Prosthetic Dentistry 1982; 47: 411-3.

Pant R, Juszczyk AS, Clark RFK and Radford RD. Long-term dimensional stability and reproduction of surface detail of four polyvinyl siloxane duplicating materials. Journal of Dentistry 2008; 36; 456-461.

Piwowarczyk A, Ottl P, Buchler A, Lauer $\mathrm{H}$ and Hoffmann A. In vitro study on the dimensional accuracy of selected materials for monophase elastic impression making. The International Journal of Prosthodontics 2002; 15: 168-174.

Purk JH, Willes MG, Tira DE, Eick JD and Hung SH. The effects of different storage conditions on polyether and polyvinylsiloxane impressions. Journal of American Dental Association 1998; 129: 1014-21.

Rosenstiel FS, Land MF and Fujimoto J. 2006. Contemporary Fixed prosthodontics. Fourth edition. Mosby. Elsevier. pp. 440-462.

Rubel BS. Impression materials: a comparative review of impression materials most commonly used in restorative dentistry. Dental Clinics of North America 2007; 51: 629646.

Schen C. Impression materials. In: Anusavice editor. Phillip’s science of dental materials. $11^{\text {th }}$ edition. Philadelphia: Saunders; 2003; pp. 210-30. 
Williams PT, Jackson DG, and Bergman W. An evaluation of the time-dependent dimensional stability of eleven elastomeric impression materials. Journal of Prosthetic Dentistry 1984; 52: 120-5.

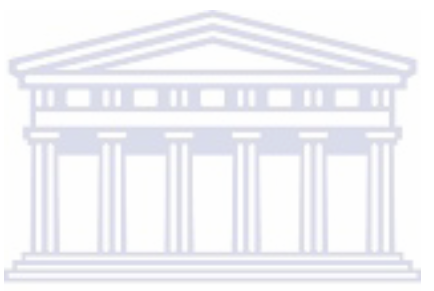

UNIVERSITY of the 


\title{
ADDENDA
}

\section{Addendum 1: Material specifications Affinis \& Impregum}

\begin{abstract}
AFFINIS $®$ PRECIOUS regular body is a silicone-based impression material for use in dentistry with automatic mixing device. It is classified as an addition-type silicone elastomer, ISO 4823, Type 2, medium consistency.

According to the manufacturers, stone models can be poured after 30 minutes at the earliest. The impression remains dimensionally stable for a practically unlimited period of time (for at least one week). They also advise to store impressions at room temperature, and avoid exposure to heat and sun.
\end{abstract}

Impregum $^{\mathrm{TM} P e n t a^{\mathrm{TM}}}$ is a medium-bodied consistency polyether impression material for the Pentamix mixing device, both products manufactured by 3M ESPE. According to the manufacturers a cast from the impression should be prepared with a specialized stone plaster no earlier than 30 min and no later than 14 days after impression taking. 


\section{Addendum 2: Digital measuring sequence using analysingDigitalImaging software version}

Fig 1: Opening page of AnalyzingDigitalImages, version 11, August 2008.

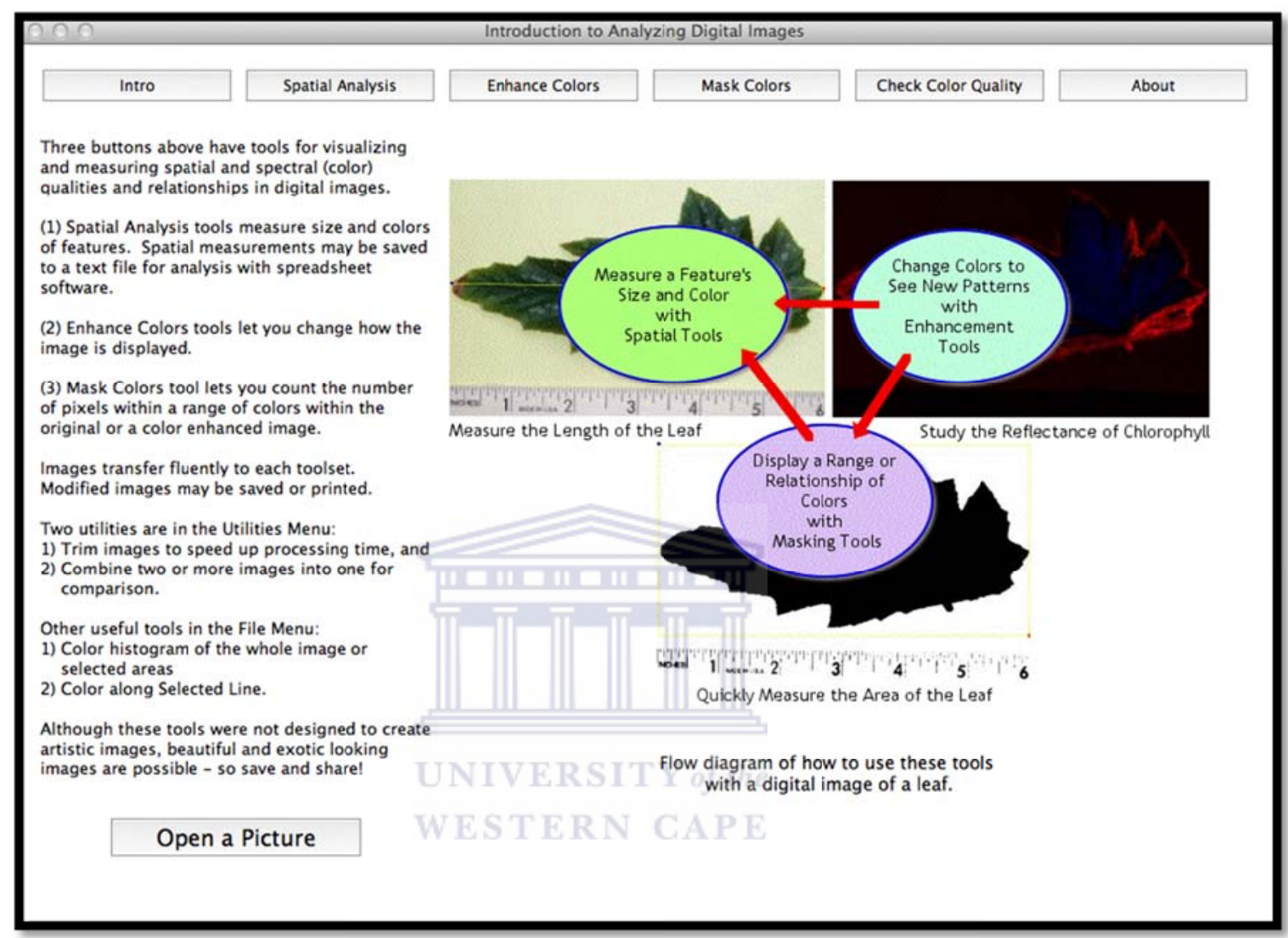

A picture needs to be opened and the tab "Spatial Analysis" is selected to start the measuring process. 
Fig 2 to 8 indicates how to manually calibrate the pixel size using a ruler with known lengths

\section{Fig 2}

Manually Calibrate The Pixel Size

1) Click on the beginning of an object of known length visible in the image.

2) Drag to the end of the scale. Release the mouse.

TIP: Draw along as much of the scale as possible. The longer the line, the more precise the measurement.

A colored line is drawn on the image. If the line does not match the scale, either redraw the line or fine tune the start and stop positions of the line with the small arrows next to the $x$ and $y$ positons of
the line end points, which are located below the image.

3) When satisfied with the fit of the line to the scale, enter the length of the scale to the scale, enter the length of the scale
used in the labeled white box below.

4) Enter two letters that represent the unit of the scale being used in the

labeled white box below. For example,

type "in" for inches and " $\mathrm{cm}$ " for

centimeters.

5) Click 'Done' when finished. To re-run the calibration method click 'Calibrate

Length' in the File menu.

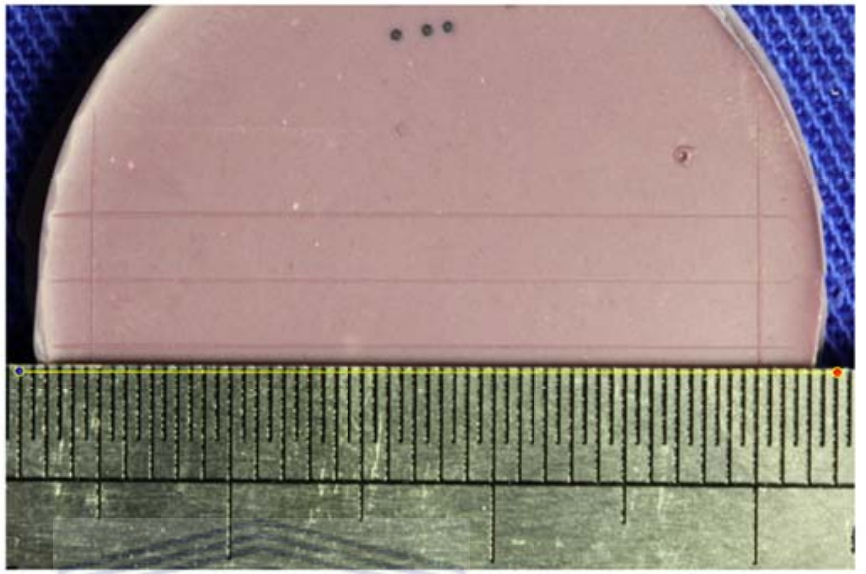

110

IMC_3772.JPC is 5184 by 3456 pixels

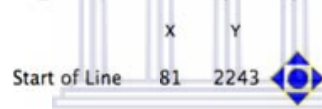

Length of Drawn Line

Unit of Length 
Fig 3

Manually Calibrate The Pixel Size

1) Click on the beginning of an object of known length visible in the image.

2) Drag to the end of the scale. Release the mouse.

TIP: Draw along as much of the scale as possible. The longer the line, the more precise the measurement.

A colored line is drawn on the image. If the line does not match the scale, either redraw the line or fine tune the start and stop positions of the line with the small arrows next to the $x$ and $y$ positons of the line end points, which are located below the image.

3) When satisfied with the fit of the line to the scale, enter the length of the scale used in the labeled white box below.

4) Enter two letters that represent the unit of the scale being used in the

labeled white box below. For example,

type "in" for
centimeters.

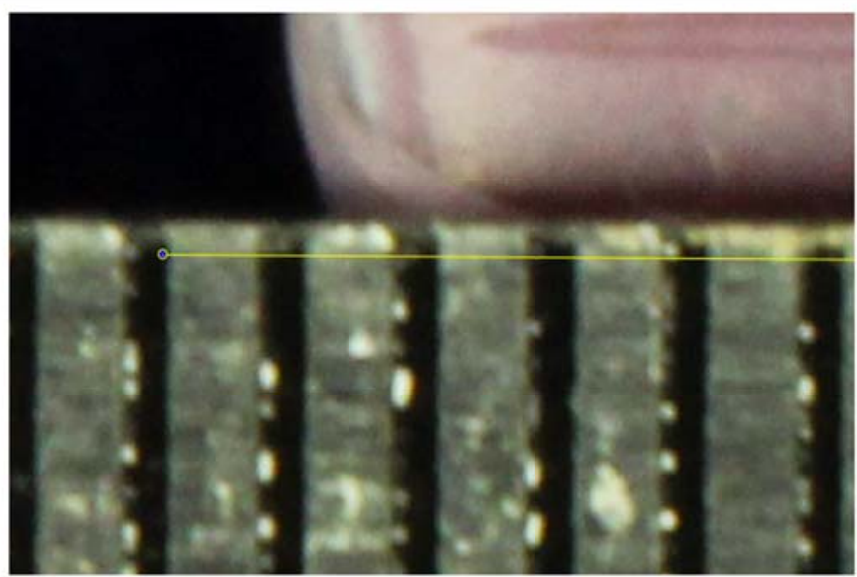

5) Click 'Done' when finished. To re-run the calibration method click 'Calibrate the calibration method c
Length' in the File menu.

IMC_3772.JPG is 5184 by 3456 pixels

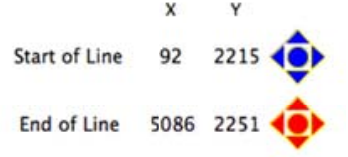

When zoomed in, pan around
the image by using the arrow zoom Magnification: Zoom keys or hold the SHIFT key and
Length of Drawn Line

Unit of Length

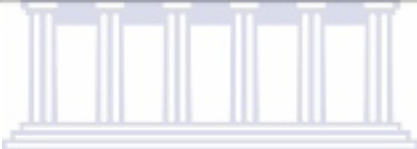

Fig 4

Manually Calibrate The Pixel Size

1) Click on the beginning of an object of known length visible in the image.

2) Drag to the end of the scale. Release the mouse.

TIP. Draw along as much of the scale as possible. The longer the line, the more precise the measurement.

A colored line is drawn on the image. If A colored line is drawn the imale. If redraw the line or fine tune scalt and stop positions of the line with the small arrows next to the $x$ and $y$ positons of the line end points, which are located below the image.

3) When satisfied with the fit of the line to the scale, enter the length of the scale used in the labeled white box below.

4) Enter two letters that represent the unit of the scale being used in the labeled white box below. For example, type "in" for inches and "cm" for centimeters.

5) Click 'Done' when finished. To re-run the calibration method click 'Calibrate Length' in the File menu.

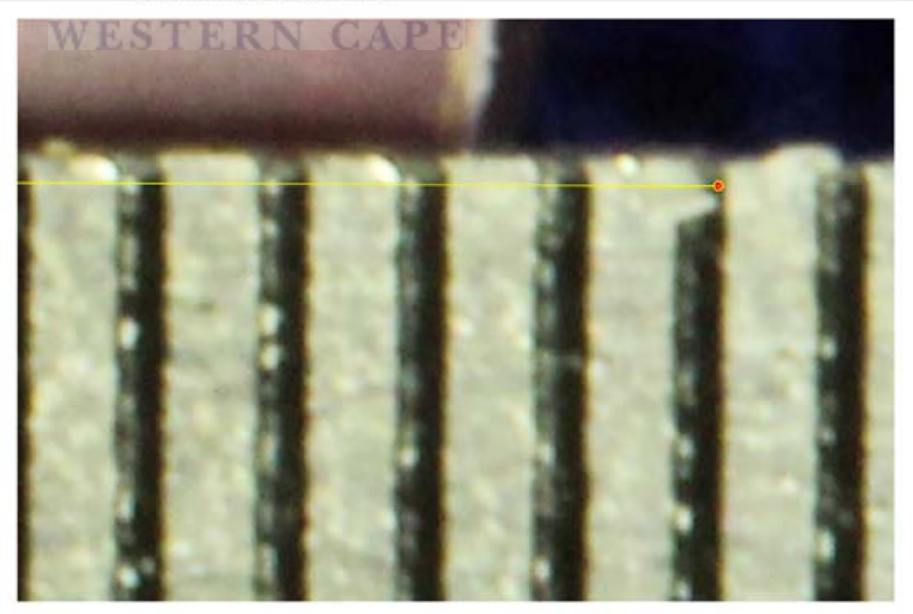

IMC_3772.JPC is 5184 by 3456 pixels

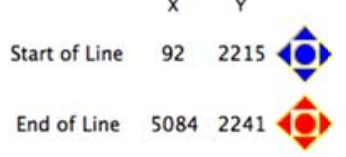

Length of Drawn Line Unit of Length

When zoomed in, pan around the image by using the arrow click and drag the image.

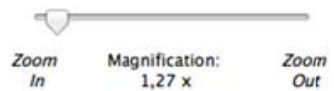


Fig 5

Manually Calibrate The Pixel Size

1) Click on the beginning of an object of known length visible in the image.

2) Drag to the end of the scale. Release the mouse.

TIP: Draw along as much of the scale as possible. The longer the line, the more precise the measurement.

A colored line is drawn on the image. If the line does not match the scale, either redraw the line or fine tune the start and stop positions of the line with the smal arrows next to the $x$ and $y$ positons of the line end points, which are located below the image.

3) When satisfied with the fit of the line to the scale, enter the length of the scale used in the labeled white box below.

4) Enter two letters that represent the unit of the scale being used in the

labeled white box below. For example, type "in" for inches and " $\mathrm{cm}$ " for

centimeters.

5) Click 'Done' when finished. To re-run the calibration method click 'Calibrate Length' in the File menu.

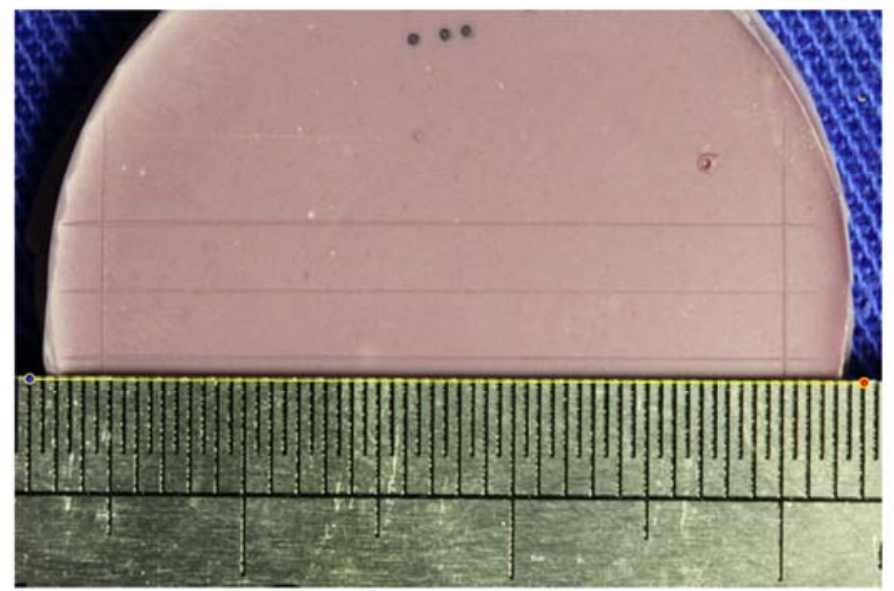

IMC_3772.JPC is 5184 by 3456 pixels

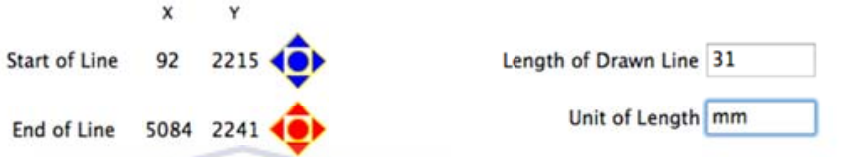

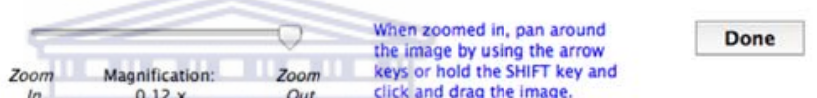

In $0.12 \times$ Click and drag the image.

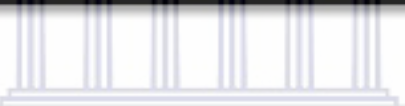

UNIVERSITY of the

Fig 6

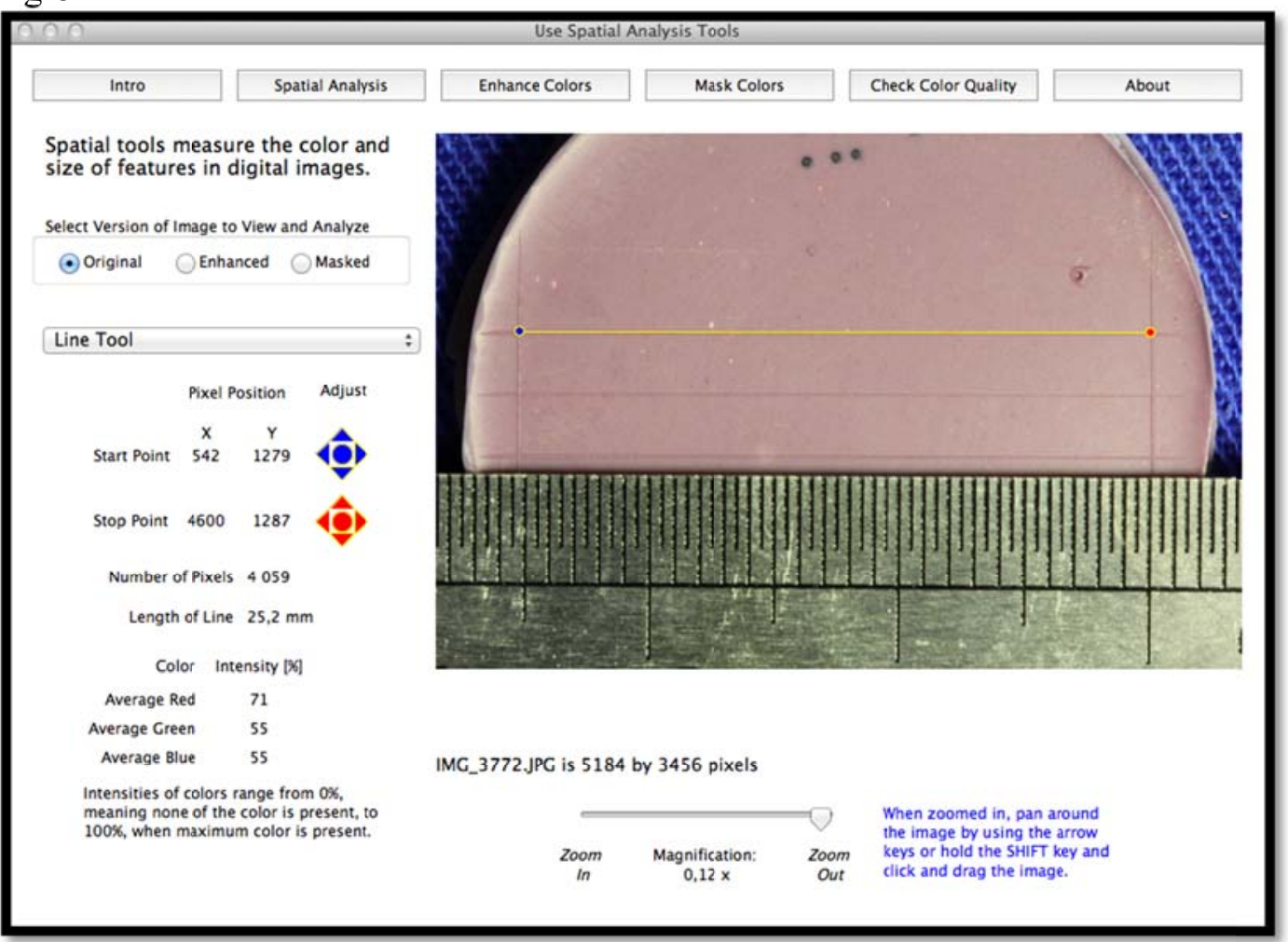


Fig 7

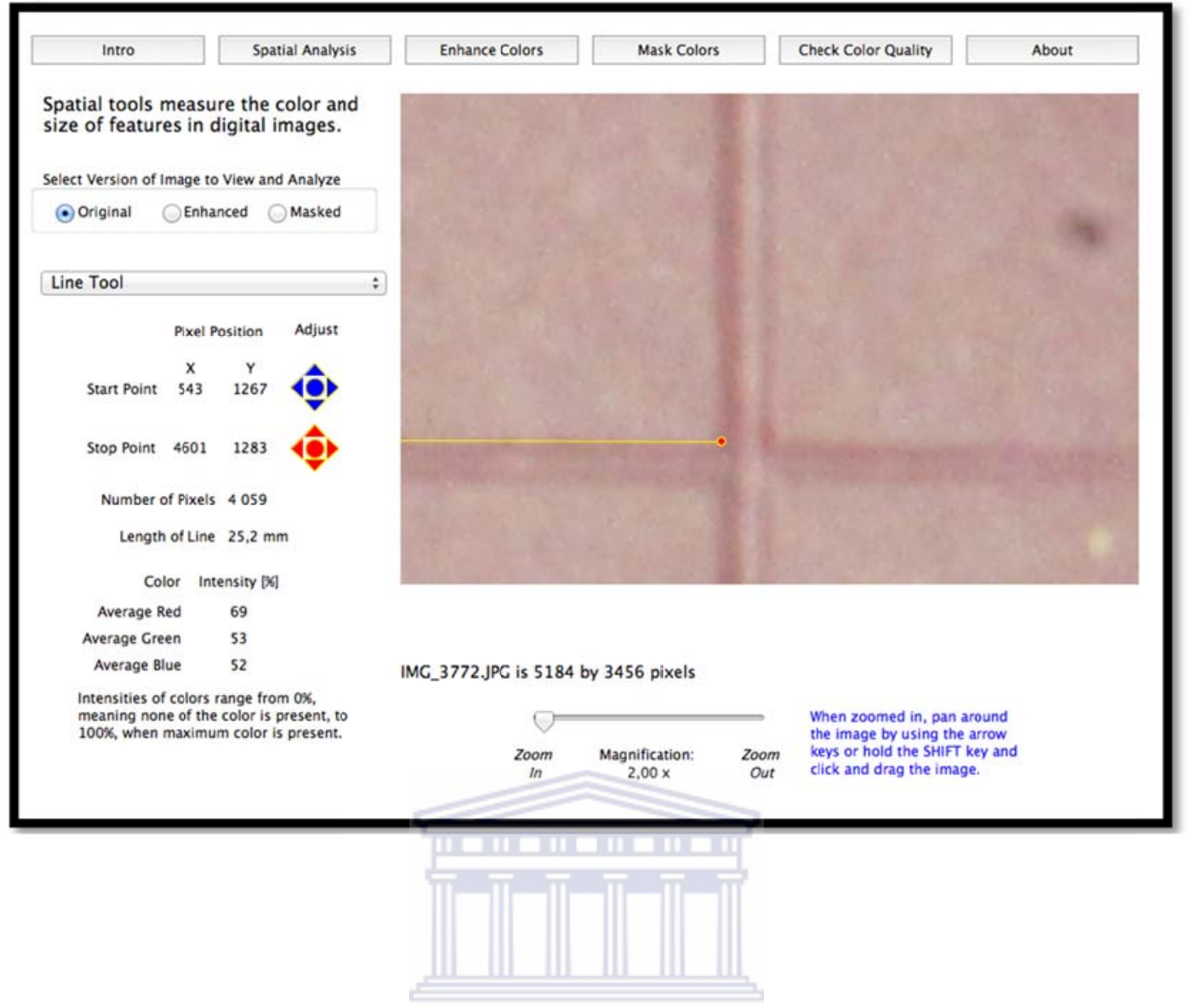

Fig 8

UNIVERSITY of the

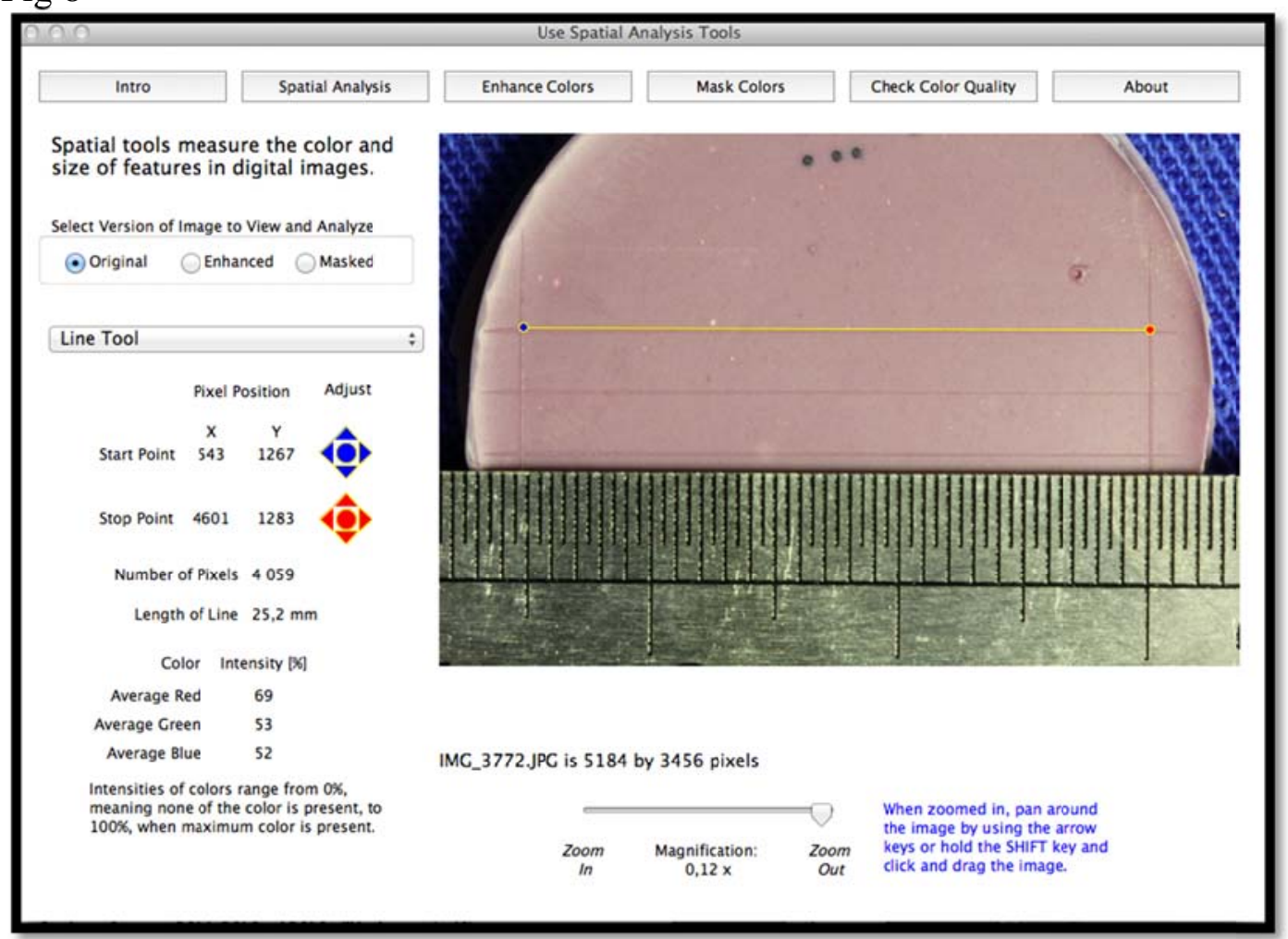




\section{Addendum 3: Data capturing sheet}

\begin{tabular}{|c|c|c|c|c|}
\hline \multicolumn{5}{|c|}{ GROUP S*21*1 } \\
\hline Specimen & $\begin{array}{l}\text { Measurement } \\
\text { (mm) }\end{array}$ & $\begin{array}{c}\text { Average } \\
\text { (L1) }\end{array}$ & $\begin{array}{l}\text { DC } \\
(\%)\end{array}$ & $\begin{array}{c}\text { Pass } \\
\text { (yes / no) }\end{array}$ \\
\hline \multicolumn{5}{|c|}{$(-2)$} \\
\hline \multicolumn{5}{|l|}{ (ii) } \\
\hline \multicolumn{5}{|l|}{ (iii) } \\
\hline \multicolumn{5}{|l|}{ (iv) } \\
\hline \multicolumn{5}{|l|}{ (v) } \\
\hline *Until n=10 & 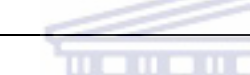 & 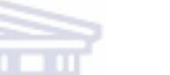 & & \\
\hline
\end{tabular}




\section{Addendum 4: Raw data (Dimensions) \& \%DC}

Table used for recording distance

\begin{tabular}{|c|c|c|c|c|}
\hline \multicolumn{5}{|c|}{ Group $S^{*} 21 * 1$} \\
\hline Specimen & Measurement (mm) & $\begin{array}{l}\text { Average } \\
(\mathrm{L} 1)\end{array}$ & $\mathrm{DC}(\%)$ & $\begin{array}{c}\text { Pass } \\
\text { (Yes/No) }\end{array}$ \\
\hline \multirow[t]{2}{*}{ DSC_0002.JPG } & 25,19546 & \multirow[t]{3}{*}{25,19748} & \multirow[t]{3}{*}{0,038864444} & \multirow[t]{3}{*}{ Yes } \\
\hline & 25,20069 & & & \\
\hline 1 & 25,19628 & & & \\
\hline \multirow[t]{3}{*}{ DSC_0003.JPG } & 25,20437 & \multirow[t]{3}{*}{25,19773} & \multirow[t]{3}{*}{0,03784622} & \multirow[t]{3}{*}{ Yes } \\
\hline & 25,20227 & & & \\
\hline & 25,18656 & & & \\
\hline \multirow[t]{3}{*}{ DSC_0004.JPG } & 25,21429 & \multirow[t]{3}{*}{25,22870} & \multirow[t]{3}{*}{$-0,085001921$} & \multirow[t]{3}{*}{ Yes } \\
\hline & 25,24527 & & & \\
\hline & 25,22654 & & & \\
\hline \multirow[t]{3}{*}{ DSC_0005.JPG } & 25,24484 & \multirow[t]{3}{*}{25,24484} & \multirow[t]{3}{*}{$-0,14903106$} & \multirow[t]{3}{*}{ Yes } \\
\hline & 25,24484 & & & \\
\hline & 25,24484 & & & \\
\hline \multirow[t]{3}{*}{ DSC_0006.JPG } & 25,24484 & \multirow{3}{*}{25,19130} & \multirow[t]{3}{*}{0,063367954} & \multirow[t]{3}{*}{ Yes } \\
\hline & 25,17345 & & & \\
\hline & 25,15561 & & & \\
\hline \multirow[t]{3}{*}{ DSC_0007.JPG } & 25,22464 & \multirow[t]{3}{*}{25,22666} & \multirow[t]{3}{*}{$-0,076922243$} & \multirow[t]{3}{*}{ Yes } \\
\hline & 25,23214 & & & \\
\hline & 25,22321 & & & \\
\hline \multirow[t]{3}{*}{ DSC_0008.JPG } & 25,25365 & \multirow{3}{*}{$\begin{array}{l}25,25295 \\
\text { CAPE }\end{array}$} & \multirow[t]{3}{*}{$-0,181204314$} & \multirow[t]{3}{*}{ Yes } \\
\hline & W E 25,25365 & & & \\
\hline & 25,25155 & & & \\
\hline \multirow[t]{3}{*}{ DSC_0009.JPG } & 25,26349 & \multirow[t]{3}{*}{25,26168} & $-0,215823951$ & Yes \\
\hline & 25,26349 & & & \\
\hline & 25,25805 & & & \\
\hline DSC_0010.JPG & 25,24370 & 25,24668 & $-0,156330541$ & Yes \\
\hline & 25,24370 & & & \\
\hline 9 & 25,25264 & & & \\
\hline DSC_0011.JPG & 25,25474 & 25,24423 & $-0,1465979$ & Yes \\
\hline & 25,23687 & & & \\
\hline 10 & 25,24107 & & & \\
\hline
\end{tabular}




\section{Group S*21*2}

\begin{tabular}{|c|c|c|c|c|}
\hline Specimen & Measurement (mm) & $\begin{array}{l}\text { Average } \\
\text { (L1) }\end{array}$ & $\mathrm{DC}(\%)$ & $\begin{array}{c}\text { Pass } \\
\text { (Yes/No) }\end{array}$ \\
\hline \multirow[t]{2}{*}{ DSC_0064.JPG } & 25,15833 & \multirow[t]{3}{*}{25,15532} & \multirow[t]{3}{*}{0,206104534} & \multirow[t]{3}{*}{ Yes } \\
\hline & 25,14930 & & & \\
\hline 1 & 25,15833 & & & \\
\hline \multirow[t]{3}{*}{ DSC_0065.JPG } & 25,12695 & \multirow[t]{3}{*}{25,13154} & \multirow[t]{3}{*}{0,300455609} & \multirow[t]{3}{*}{ Yes } \\
\hline & 25,11792 & & & \\
\hline & 25,14974 & & & \\
\hline \multirow{3}{*}{ DSC_0066.JPG } & 25,14716 & \multirow[t]{3}{*}{25,14945} & \multirow[t]{3}{*}{0,229391464} & \multirow[t]{3}{*}{ Yes } \\
\hline & 25,15618 & & & \\
\hline & 25,14501 & & & \\
\hline \multirow[t]{3}{*}{ DSC_0067.JPG } & 25,14759 & \multirow[t]{3}{*}{25,14902} & \multirow[t]{3}{*}{0,231084097} & \multirow[t]{3}{*}{ Yes } \\
\hline & 25,14974 & & & \\
\hline & 25,14974 & & & \\
\hline \multirow[t]{3}{*}{ DSC_0068.JPG } & 25,13953 & \multirow[t]{3}{*}{25,13953} & \multirow[t]{3}{*}{0,268745185} & \multirow[t]{3}{*}{ Yes } \\
\hline & 25,13953 & & & \\
\hline & 25,13953 & & & \\
\hline \multirow[t]{3}{*}{ DSC_0069.JPG } & 25,14856 & \multirow[t]{3}{*}{25,14498} & \multirow[t]{3}{*}{0,247124441} & \multirow[t]{3}{*}{ Yes } \\
\hline & 25,13782 & & & \\
\hline & 25,14856 & & & \\
\hline \multirow[t]{3}{*}{ DSC_0070.JPG } & 25,16099 & \multirow{3}{*}{25,16156} & \multirow[t]{3}{*}{0,181362998} & \multirow[t]{3}{*}{ Yes } \\
\hline & 25,16099 & & & \\
\hline & 25,16269 & & & \\
\hline \multirow[t]{3}{*}{ DSC_0071.JPG } & 25,13953 & \multirow[t]{3}{*}{25,13953} & 0,268745185 & Yes \\
\hline & 25,13953 & & & \\
\hline & 25,13953 & & & \\
\hline DSC_0072.JPG & $\begin{array}{l}0,16306 \\
\end{array}$ & $x$ of 25,15776 & 0,196424789 & Yes \\
\hline & $\begin{array}{ll}W & 25,15404\end{array}$ & & & \\
\hline 9 & 25,15618 & & & \\
\hline DSC_0073.JPG & 25,14759 & 25,14601 & 0,243025095 & Yes \\
\hline & 25,14974 & & & \\
\hline 10 & 25,14071 & & & \\
\hline
\end{tabular}




\section{Group S*21*3}

\begin{tabular}{|c|c|c|c|c|}
\hline Specimen & Measurement (mm) & $\begin{array}{l}\text { Average } \\
\text { (L1) }\end{array}$ & $\mathrm{DC}(\%)$ & $\begin{array}{c}\text { Pass } \\
\text { (Yes/No) }\end{array}$ \\
\hline \multirow[t]{3}{*}{ IMG_3730.JPG } & 25,20648 & \multirow[t]{3}{*}{25,20441} & \multirow[t]{3}{*}{0,011345932} & \multirow[t]{3}{*}{ Yes } \\
\hline & 25,20028 & & & \\
\hline & 25,20648 & & & \\
\hline \multirow[t]{3}{*}{ IMG_3731.JPG } & 25,22323 & \multirow[t]{3}{*}{25,22157} & \multirow[t]{3}{*}{$-0,056716434$} & \multirow[t]{3}{*}{ Yes } \\
\hline & 25,21825 & & & \\
\hline & 25,22323 & & & \\
\hline \multirow[t]{3}{*}{ IMG_3732.JPG } & 25,19573 & \multirow[t]{3}{*}{25,20071} & \multirow[t]{3}{*}{0,026024235} & \multirow[t]{3}{*}{ Yes } \\
\hline & 25,20475 & & & \\
\hline & 25,20166 & & & \\
\hline \multirow[t]{3}{*}{ IMG_3733.JPG } & 25,17453 & \multirow[t]{3}{*}{25,18445} & \multirow[t]{3}{*}{0,090555874} & \multirow[t]{3}{*}{ Yes } \\
\hline & 25,19833 & & & \\
\hline & 25,18048 & & & \\
\hline \multirow[t]{3}{*}{ IMG_3734.JPG } & 25,20285 & \multirow[t]{3}{*}{25,20317} & \multirow[t]{3}{*}{0,016291594} & \multirow[t]{3}{*}{ Yes } \\
\hline & 25,20285 & & & \\
\hline & 25,20380 & & & \\
\hline \multirow[t]{3}{*}{ IMG_3735.JPG } & 25,19952 & \multirow[t]{3}{*}{25,19786} & \multirow[t]{3}{*}{0,037356943} & \multirow[t]{3}{*}{ Yes } \\
\hline & 25,20048 & & & \\
\hline & 25,19357 & & & \\
\hline \multirow[t]{3}{*}{ IMG_3736.JPG } & 25,23470 & \multirow{3}{*}{25,23105} & \multirow[t]{3}{*}{$-0,094337851$} & \multirow[t]{3}{*}{ Yes } \\
\hline & 25,22970 & & & \\
\hline & 25,22876 & & & \\
\hline \multirow[t]{3}{*}{ IMG_3737.JPG } & 25,20143 & \multirow{3}{*}{25,20175} & \multirow[t]{3}{*}{0,021924889} & Yes \\
\hline & 25,20238 & & & \\
\hline & 25,20143 & & & \\
\hline IMG_3739.JPG & $\begin{array}{l}25,20072 \\
\end{array}$ & $x$ of 25,20072 & 0,025997787 & Yes \\
\hline & W F $\quad 25,20072$ & CAPE & & \\
\hline 9 & 25,20072 & & & \\
\hline IMG_3740.JPG & 25,19357 & 25,21247 & $-0,020628967$ & Yes \\
\hline & 25,25124 & & & \\
\hline 10 & 25,19261 & & & \\
\hline
\end{tabular}




\begin{tabular}{|c|c|c|c|c|}
\hline \multicolumn{5}{|c|}{ Group S*66*1 } \\
\hline Specimen & Measurement (mm) & $\begin{array}{c}\text { Average } \\
(\mathrm{L} 1)\end{array}$ & $\mathrm{DC}(\%)$ & $\begin{array}{c}\text { Pass } \\
\text { (Yes/No) }\end{array}$ \\
\hline \multirow[t]{3}{*}{ DSC_0025.JPG } & 25,25206 & \multirow[t]{3}{*}{25,24534} & \multirow[t]{3}{*}{$-0,151027838$} & \multirow[t]{3}{*}{ Yes } \\
\hline & 25,24534 & & & \\
\hline & 25,23863 & & & \\
\hline \multirow[t]{3}{*}{ DSC_0026.JPG } & 25,24134 & \multirow[t]{3}{*}{25,24492} & \multirow[t]{3}{*}{$-0,149335205$} & \multirow[t]{3}{*}{ Yes } \\
\hline & 25,25026 & & & \\
\hline & 25,24315 & & & \\
\hline \multirow[t]{3}{*}{ DSC_0027.JPG } & 25,23372 & \multirow[t]{3}{*}{25,23145} & \multirow[t]{3}{*}{$-0,095898247$} & \multirow[t]{3}{*}{ Yes } \\
\hline & 25,22690 & & & \\
\hline & 25,23372 & & & \\
\hline \multirow[t]{3}{*}{ DSC_0028.JPG } & 25,23423 & \multirow[t]{3}{*}{25,23273} & \multirow[t]{3}{*}{$-0,100976147$} & \multirow[t]{3}{*}{ Yes } \\
\hline & 25,22972 & & & \\
\hline & 25,23423 & & & \\
\hline \multirow[t]{3}{*}{ DSC_0029.JPG } & 25,22581 & \multirow[t]{3}{*}{25,22622} & \multirow[t]{3}{*}{$-0,075176715$} & \multirow[t]{3}{*}{ Yes } \\
\hline & 25,22754 & & & \\
\hline & 25,22532 & & & \\
\hline \multirow[t]{3}{*}{ DSC_0030.JPG } & 25,24107 & \multirow[t]{3}{*}{25,23949} & \multirow[t]{3}{*}{$-0,127820251$} & \multirow[t]{3}{*}{ Yes } \\
\hline & 25,24317 & & & \\
\hline & 25,23424 & & & \\
\hline \multirow[t]{3}{*}{ DSC_0031.JPG } & 25,23267 & \multirow[t]{3}{*}{25,23039} & \multirow[t]{3}{*}{$-0,091706336$} & \multirow[t]{3}{*}{ Yes } \\
\hline & 25,22583 & & & \\
\hline & 25,23267 & & & \\
\hline \multirow[t]{3}{*}{ DSC_0032.JPG } & 25,19220 & \multirow[t]{3}{*}{25,19377} & 0,053569195 & Yes \\
\hline & 25,19691 & & & \\
\hline & 25,19220 & & & \\
\hline DSC_0033.JPG & W $\quad 25,22846$ & CAP 25,22951 & $-0,088228503$ & Yes \\
\hline & 25,23004 & & & \\
\hline 9 & 25,23004 & & & \\
\hline DSC_0034.JPG & 25,23793 & 25,23793 & $-0,121618337$ & Yes \\
\hline & 25,23793 & & & \\
\hline 10 & 25,23793 & & & \\
\hline
\end{tabular}




\begin{tabular}{|c|c|c|c|c|}
\hline \multicolumn{5}{|c|}{ Group $S * 66 * 2$} \\
\hline Specimen & Measurement (mm) & $\begin{array}{c}\text { Average } \\
\text { (L1) }\end{array}$ & $\mathrm{DC}(\%)$ & $\begin{array}{c}\text { Pass } \\
\text { (Yes/No) }\end{array}$ \\
\hline \multirow{2}{*}{ DSC_0105.JPG } & 25,14617 & \multirow{3}{*}{25,14327} & \multirow{3}{*}{0,253908197} & \multirow{3}{*}{ Yes } \\
\hline & 25,14617 & & & \\
\hline 1 & 25,13747 & & & \\
\hline \multirow[t]{3}{*}{ DSC_0106.JPG } & 25,11491 & \multirow[t]{3}{*}{25,12712} & \multirow[t]{3}{*}{0,317990231} & \multirow[t]{3}{*}{ Yes } \\
\hline & 25,12980 & & & \\
\hline & 25,13664 & & & \\
\hline \multirow[t]{3}{*}{ DSC_0107.JPG } & 25,16649 & \multirow[t]{3}{*}{25,15488} & \multirow[t]{3}{*}{0,207850062} & \multirow[t]{3}{*}{ Yes } \\
\hline & 25,14037 & & & \\
\hline & 25,15778 & & & \\
\hline \multirow[t]{3}{*}{ DSC_0108.JPG } & 25,14867 & \multirow[t]{3}{*}{25,14936} & \multirow[t]{3}{*}{0,229748504} & \multirow[t]{3}{*}{ Yes } \\
\hline & 25,15074 & & & \\
\hline & 25,14867 & & & \\
\hline \multirow[t]{2}{*}{ DSC_0109.JPG } & 25,14244 & \multirow[t]{3}{*}{25,13906} & \multirow[t]{3}{*}{0,270596502} & \multirow[t]{3}{*}{ Yes } \\
\hline & 25,13372 & & & \\
\hline 5 & 25,14103 & & & \\
\hline \multirow[t]{2}{*}{ DSC_0110.JPG } & 25,15406 & \multirow[t]{3}{*}{25,15924} & \multirow[t]{3}{*}{0,190540244} & \multirow[t]{3}{*}{ Yes } \\
\hline & 25,16090 & & & \\
\hline 6 & 25,16277 & & & \\
\hline \multirow[t]{2}{*}{ DSC_0111.JPG } & 25,10060 & \multirow[t]{3}{*}{25,10185} & \multirow[t]{3}{*}{0,418225851} & \multirow[t]{3}{*}{ Yes } \\
\hline & 25,10060 & & & \\
\hline 7 & 25,10435 & & & \\
\hline \multirow[t]{2}{*}{ DSC_0112.JPG } & 25,14721 & \multirow[t]{3}{*}{25,13788} & 0,275277691 & Yes \\
\hline & 25,12980 & & & \\
\hline 8 & 25,13664 & & & \\
\hline DSC_0113.JPG & W 25,10555 & CAP25,09974 & 0,426583227 & Yes \\
\hline & 25,09684 & & & \\
\hline 9 & 25,09684 & & & \\
\hline DSC_0114.JPG & 25,11238 & 25,11176 & 0,378925025 & Yes \\
\hline & 25,11051 & & & \\
\hline 10 & 25,11238 & & & \\
\hline
\end{tabular}




\begin{tabular}{|c|c|c|c|c|}
\hline \multicolumn{5}{|c|}{ Group S*66*3 } \\
\hline Specimen & Measurement (mm) & $\begin{array}{c}\text { Average } \\
(\mathrm{L} 1)\end{array}$ & $\mathrm{DC}(\%)$ & $\begin{array}{c}\text { Pass } \\
\text { (Yes/No) }\end{array}$ \\
\hline \multirow[t]{3}{*}{ IMG_3753.JPG } & 25,23097 & \multirow[t]{3}{*}{25,23006} & \multirow[t]{3}{*}{$-0,090383966$} & \multirow[t]{3}{*}{ Yes } \\
\hline & 25,23718 & & & \\
\hline & 25,22202 & & & \\
\hline \multirow[t]{3}{*}{ IMG_3754.JPG } & 25,22750 & \multirow[t]{3}{*}{25,23371} & \multirow[t]{3}{*}{$-0,104890361$} & \multirow[t]{3}{*}{ Yes } \\
\hline & 25,23371 & & & \\
\hline & 25,23993 & & & \\
\hline \multirow[t]{2}{*}{ IMG_3755.JPG } & 25,23602 & \multirow[t]{3}{*}{25,23395} & \multirow[t]{3}{*}{$-0,105829243$} & \multirow[t]{3}{*}{ Yes } \\
\hline & 25,23602 & & & \\
\hline 3 & 25,22981 & & & \\
\hline \multirow[t]{3}{*}{ IMG_3756.JPG } & 25,22129 & \multirow[t]{3}{*}{25,22206} & \multirow[t]{3}{*}{$-0,058660318$} & \multirow[t]{3}{*}{ Yes } \\
\hline & 25,22129 & & & \\
\hline & 25,22360 & & & \\
\hline \multirow[t]{2}{*}{ IMG_3757.JPG } & 25,25396 & \multirow[t]{3}{*}{25,24774} & \multirow[t]{3}{*}{$-0,1605489$} & \multirow[t]{3}{*}{ Yes } \\
\hline & 25,25396 & & & \\
\hline 5 & 25,23531 & & & \\
\hline \multirow[t]{3}{*}{ IMG_3758.JPG } & 25,24357 & \multirow[t]{3}{*}{25,24941} & \multirow[t]{3}{*}{$-0,167173972$} & \multirow[t]{3}{*}{ Yes } \\
\hline & 25,25487 & & & \\
\hline & 25,24980 & & & \\
\hline \multirow[t]{3}{*}{ IMG_3759.JPG } & 25,22720 & \multirow[t]{3}{*}{25,22590} & \multirow[t]{3}{*}{$-0,073880793$} & \multirow[t]{3}{*}{ Yes } \\
\hline & 25,22720 & & & \\
\hline & 25,22329 & & & \\
\hline \multirow[t]{3}{*}{ IMG_3760.JPG } & 25,21823 & \multirow[t]{3}{*}{25,21654} & $-0,0367751$ & Yes \\
\hline & 25,21201 & & & \\
\hline & 25,21939 & & & \\
\hline IMG_3761.JPG & W $\quad 25,21939$ & CAP 25,22016 & $-0,051136035$ & Yes \\
\hline & 25,21939 & & & \\
\hline 9 & 25,22171 & & & \\
\hline IMG_3762.JPG & 25,22634 & 25,22726 & $-0,079289284$ & Yes \\
\hline & 25,22013 & & & \\
\hline 10 & 25,23531 & & & \\
\hline
\end{tabular}




\begin{tabular}{|c|c|c|c|c|}
\hline \multicolumn{5}{|c|}{ Group $P^{*} 21 * 1$} \\
\hline Specimen & Measurement (mm) & $\begin{array}{c}\text { Average } \\
(\mathrm{L} 1)\end{array}$ & $\mathrm{DC}(\%)$ & $\begin{array}{c}\text { Pass } \\
\text { (Yes/No) }\end{array}$ \\
\hline \multirow[t]{4}{*}{ DSC_0015.JPG } & 25,19214 & \multirow[t]{4}{*}{25,20352} & \multirow[t]{4}{*}{0,014909718} & \multirow[t]{4}{*}{ Yes } \\
\hline & 25,21338 & & & \\
\hline & 25,19979 & & & \\
\hline & 25,20875 & & & \\
\hline \multirow[t]{3}{*}{ DSC_0016.JPG } & 25,15338 & \multirow[t]{3}{*}{25,14742} & \multirow[t]{3}{*}{0,237457919} & \multirow[t]{3}{*}{ Yes } \\
\hline & 25,13549 & & & \\
\hline & 25,15338 & & & \\
\hline \multirow[t]{3}{*}{ DSC_0017.JPG } & 25,16394 & \multirow[t]{3}{*}{25,17600} & \multirow[t]{3}{*}{0,124064721} & \multirow[t]{3}{*}{ Yes } \\
\hline & 25,18883 & & & \\
\hline & 25,17523 & & & \\
\hline \multirow[t]{3}{*}{ DSC_0018.JPG } & 25,15731 & \multirow[t]{3}{*}{25,16018} & \multirow[t]{3}{*}{0,186837609} & \multirow[t]{3}{*}{ Yes } \\
\hline & 25,16161 & & & \\
\hline & 25,16161 & & & \\
\hline \multirow[t]{2}{*}{ DSC_0019.JPG } & 25,17756 & \multirow[t]{3}{*}{25,17911} & \multirow[t]{3}{*}{0,111740236} & \multirow[t]{3}{*}{ Yes } \\
\hline & 25,17988 & & & \\
\hline 5 & 25,17988 & & & \\
\hline \multirow[t]{3}{*}{ DSC_0020.JPG } & 25,16627 & \multirow[t]{3}{*}{25,17446} & \multirow[t]{3}{*}{0,130187293} & \multirow[t]{3}{*}{ Yes } \\
\hline & 25,18187 & & & \\
\hline & 25,17523 & & & \\
\hline \multirow[t]{3}{*}{ DSC_0021.JPG } & 25,17954 & \multirow[t]{3}{*}{25,18187} & \multirow[t]{3}{*}{0,100791015} & \multirow[t]{3}{*}{ Yes } \\
\hline & 25,19083 & & & \\
\hline & 25,17523 & & & \\
\hline \multirow[t]{3}{*}{ DSC_0022.JPG } & 25,17523 & 25,18431 & 0,091098046 & Yes \\
\hline & 25,18618 & Y of the & & \\
\hline & W $\quad 25,19152$ & $\mathrm{CAPD}$ & & \\
\hline DSC_0023.JPG & 25,18187 & 25,18563 & 0,085861462 & Yes \\
\hline & 25,19083 & & & \\
\hline 9 & 25,18419 & & & \\
\hline DSC_0024.JPG & 25,17756 & 25,17756 & 0,117876031 & Yes \\
\hline & 25,17756 & & & \\
\hline 10 & 25,17756 & & & \\
\hline
\end{tabular}




\begin{tabular}{|c|c|c|c|c|}
\hline \multicolumn{5}{|c|}{ Group $P^{*} 21 * 2$} \\
\hline Specimen & Measurement (mm) & $\begin{array}{c}\text { Average } \\
(\mathrm{L} 1)\end{array}$ & $\mathrm{DC}(\%)$ & $\begin{array}{c}\text { Pass } \\
\text { (Yes/No) }\end{array}$ \\
\hline \multirow[t]{3}{*}{ DSC_0074.JPG } & 25,13383 & \multirow[t]{3}{*}{25,13140} & \multirow{3}{*}{0,301011004} & \multirow[t]{3}{*}{ Yes } \\
\hline & 25,13813 & & & \\
\hline & 25,12223 & & & \\
\hline \multirow[t]{3}{*}{ DSC_0075.JPG } & 25,12264 & \multirow[t]{3}{*}{25,11877} & \multirow[t]{3}{*}{0,351089143} & \multirow[t]{3}{*}{ Yes } \\
\hline & 25,10889 & & & \\
\hline & 25,12479 & & & \\
\hline \multirow[t]{3}{*}{ DSC_0076.JPG } & 25,11105 & \multirow[t]{3}{*}{25,10732} & \multirow[t]{3}{*}{0,396525765} & \multirow[t]{3}{*}{ Yes } \\
\hline & 25,10889 & & & \\
\hline & 25,10202 & & & \\
\hline \multirow[t]{3}{*}{ DSC_0077.JPG } & 25,10964 & \multirow[t]{3}{*}{25,10663} & \multirow[t]{3}{*}{0,39926307} & \multirow[t]{3}{*}{ Yes } \\
\hline & 25,10061 & & & \\
\hline & 25,10964 & & & \\
\hline \multirow[t]{3}{*}{ DSC_0078.JPG } & 25,12673 & \multirow[t]{3}{*}{25,12738} & \multirow[t]{3}{*}{0,316958783} & \multirow[t]{3}{*}{ Yes } \\
\hline & 25,12673 & & & \\
\hline & 25,12867 & & & \\
\hline \multirow[t]{3}{*}{ DSC_0079.JPG } & 25,09825 & \multirow[t]{3}{*}{25,10126} & \multirow[t]{3}{*}{0,420566445} & \multirow[t]{3}{*}{ Yes } \\
\hline & 25,09825 & & & \\
\hline & 25,10728 & & & \\
\hline \multirow[t]{3}{*}{ DSC_0080.JPG } & 25,09770 & \multirow[t]{3}{*}{25,10300} & \multirow[t]{3}{*}{0,413650452} & \multirow[t]{3}{*}{ Yes } \\
\hline & 25,09770 & & & \\
\hline & 25,11361 & & & \\
\hline \multirow[t]{3}{*}{ DSC_0081.JPG } & 25,10202 & \multirow[t]{3}{*}{25,09829} & 0,432348759 & Yes \\
\hline & 25,09083 & & & \\
\hline & 25,10202 & & & \\
\hline DSC_0082.JPG & W 25,11105 & CAP 25,11105 & 0,381728448 & Yes \\
\hline & 25,11105 & & & \\
\hline 9 & 25,11105 & & & \\
\hline DSC_0083.JPG & 25,14772 & 25,14929 & 0,230039425 & Yes \\
\hline & 25,15242 & & & \\
\hline 10 & 25,14772 & & & \\
\hline
\end{tabular}




\begin{tabular}{|c|c|c|c|c|}
\hline \multicolumn{5}{|c|}{ Group $P^{*} 21 * 3$} \\
\hline Specimen & Measurement (mm) & $\begin{array}{c}\text { Average } \\
(\mathrm{L} 1)\end{array}$ & $\mathrm{DC}(\%)$ & $\begin{array}{c}\text { Pass } \\
\text { (Yes/No) }\end{array}$ \\
\hline \multirow[t]{3}{*}{ IMG_3742.JPG } & 25,25035 & \multirow[t]{3}{*}{25,25264} & \multirow{3}{*}{$-0,17997451$} & \multirow[t]{3}{*}{ Yes } \\
\hline & 25,25628 & & & \\
\hline & 25,25129 & & & \\
\hline \multirow[t]{3}{*}{ IMG_3743.JPG } & 25,21782 & \multirow[t]{3}{*}{25,22083} & \multirow[t]{3}{*}{$-0,053793998$} & \multirow[t]{3}{*}{ Yes } \\
\hline & 25,22092 & & & \\
\hline & 25,22376 & & & \\
\hline \multirow[t]{2}{*}{ IMG_3744.JPG } & 25,20854 & \multirow[t]{3}{*}{25,20625} & \multirow[t]{3}{*}{0,004072899} & \multirow[t]{3}{*}{ Yes } \\
\hline & 25,19668 & & & \\
\hline 3 & 25,21352 & & & \\
\hline \multirow[t]{3}{*}{ IMG_3745.JPG } & 25,19573 & \multirow[t]{3}{*}{25,20174} & \multirow[t]{3}{*}{0,021938113} & \multirow[t]{3}{*}{ Yes } \\
\hline & 25,20475 & & & \\
\hline & 25,20475 & & & \\
\hline \multirow[t]{3}{*}{ IMG_3746.JPG } & 25,21860 & \multirow[t]{3}{*}{25,21923} & \multirow[t]{3}{*}{$-0,047446623$} & \multirow[t]{3}{*}{ Yes } \\
\hline & 25,21955 & & & \\
\hline & 25,21955 & & & \\
\hline \multirow[t]{3}{*}{ IMG_3747.JPG } & 25,19715 & \multirow[t]{3}{*}{25,19850} & \multirow[t]{3}{*}{0,034817993} & \multirow[t]{3}{*}{ Yes } \\
\hline & 25,19715 & & & \\
\hline & 25,20119 & & & \\
\hline \multirow[t]{3}{*}{ IMG_3748.JPG } & 25,19905 & \multirow[t]{3}{*}{25,19842} & \multirow[t]{3}{*}{0,035135362} & \multirow[t]{3}{*}{ Yes } \\
\hline & 25,19810 & & & \\
\hline & 25,19810 & & & \\
\hline \multirow[t]{3}{*}{ IMG_3749.JPG } & 25,19799 & \multirow[t]{3}{*}{25,19631} & 0,043505962 & Yes \\
\hline & 25,19799 & & & \\
\hline & 25,19294 & & & \\
\hline IMG_3750.JPG & W $\quad 25,21309$ & CAP 25,21515 & $-0,031260819$ & Yes \\
\hline & 25,20804 & & & \\
\hline 9 & 25,22433 & & & \\
\hline IMG_3751.JPG & 25,26348 & 25,26206 & $-0,2173579$ & Yes \\
\hline & 25,26479 & & & \\
\hline 10 & 25,25792 & & & \\
\hline
\end{tabular}




\begin{tabular}{|c|c|c|c|c|}
\hline \multicolumn{5}{|c|}{ Group P*66*1 } \\
\hline Specimen & Measurement (mm) & $\begin{array}{c}\text { Average } \\
(\mathrm{L} 1)\end{array}$ & $\mathrm{DC}(\%)$ & $\begin{array}{c}\text { Pass } \\
\text { (Yes/No) }\end{array}$ \\
\hline \multirow[t]{3}{*}{ DSC_0035.JPG } & 25,24961 & \multirow{3}{*}{25,24100} & \multirow{3}{*}{$-0,133797362$} & \multirow[t]{3}{*}{ Yes } \\
\hline & 25,24120 & & & \\
\hline & 25,23219 & & & \\
\hline \multirow[t]{3}{*}{ DSC_0036.JPG } & 25,19185 & \multirow[t]{3}{*}{25,18585} & \multirow[t]{3}{*}{0,084988698} & \multirow[t]{3}{*}{ Yes } \\
\hline & 25,18285 & & & \\
\hline & 25,18285 & & & \\
\hline \multirow[t]{3}{*}{ DSC_0037.JPG } & 25,25732 & \multirow[t]{3}{*}{25,25732} & \multirow[t]{3}{*}{$-0,19854058$} & \multirow[t]{3}{*}{ Yes } \\
\hline & 25,25732 & & & \\
\hline & 25,25732 & & & \\
\hline \multirow[t]{3}{*}{ DSC_0038.JPG } & 25,16340 & \multirow[t]{3}{*}{25,16040} & \multirow[t]{3}{*}{0,185938397} & \multirow[t]{3}{*}{ Yes } \\
\hline & 25,14756 & & & \\
\hline & 25,17025 & & & \\
\hline \multirow[t]{3}{*}{ DSC_0039.JPG } & 25,14921 & \multirow[t]{3}{*}{25,14621} & \multirow[t]{3}{*}{0,242244897} & \multirow[t]{3}{*}{ Yes } \\
\hline & 25,14921 & & & \\
\hline & 25,14021 & & & \\
\hline \multirow[t]{3}{*}{ DSC_0040.JPG } & 25,05263 & \multirow[t]{3}{*}{25,05421} & \multirow[t]{3}{*}{0,607218922} & \multirow[t]{3}{*}{ Yes } \\
\hline & 25,05500 & & & \\
\hline & 25,05500 & & & \\
\hline \multirow[t]{3}{*}{ DSC_0041.JPG } & 25,15586 & \multirow[t]{3}{*}{25,15286} & \multirow[t]{3}{*}{0,215863622} & \multirow[t]{3}{*}{ Yes } \\
\hline & 25,15586 & & & \\
\hline & 25,14686 & & & \\
\hline \multirow[t]{3}{*}{ DSC_0042.JPG } & 25,10188 & \multirow[t]{3}{*}{25,10109} & 0,42122763 & Yes \\
\hline & 25,09288 & & & \\
\hline & 25,10852 & & & \\
\hline DSC_0043.JPG & W $\quad 25,11558$ & CAP 25,12679 & 0,319299377 & Yes \\
\hline & 25,13356 & & & \\
\hline 9 & 25,13122 & & & \\
\hline DSC_0044.JPG & 25,13514 & 25,13800 & 0,274814862 & Yes \\
\hline & 25,13943 & & & \\
\hline 10 & 25,13943 & & & \\
\hline
\end{tabular}




\begin{tabular}{|c|c|c|c|c|}
\hline \multicolumn{5}{|c|}{ Group $P^{*} 66 * 2$} \\
\hline Specimen & Measurement (mm) & $\begin{array}{c}\text { Average } \\
(\mathrm{L} 1)\end{array}$ & $\mathrm{DC}(\%)$ & $\begin{array}{c}\text { Pass } \\
\text { (Yes/No) }\end{array}$ \\
\hline \multirow[t]{3}{*}{ DSC_0095.JPG } & 25,10264 & \multirow[t]{3}{*}{25,12137} & \multirow{3}{*}{0,340801107} & \multirow[t]{3}{*}{ Yes } \\
\hline & 25,13166 & & & \\
\hline & 25,12980 & & & \\
\hline \multirow[t]{3}{*}{ DSC_0096.JPG } & 25,13539 & \multirow[t]{3}{*}{25,13760} & \multirow[t]{3}{*}{0,276388482} & \multirow[t]{3}{*}{ Yes } \\
\hline & 25,14203 & & & \\
\hline & 25,13539 & & & \\
\hline \multirow[t]{3}{*}{ DSC_0097.JPG } & 25,13850 & \multirow[t]{3}{*}{25,13270} & \multirow[t]{3}{*}{0,295840539} & \multirow[t]{3}{*}{ Yes } \\
\hline & 25,12980 & & & \\
\hline & 25,12980 & & & \\
\hline \multirow[t]{3}{*}{ DSC_0098.JPG } & 25,12857 & \multirow[t]{3}{*}{25,12402} & \multirow[t]{3}{*}{0,330288269} & \multirow[t]{3}{*}{ Yes } \\
\hline & 25,12174 & & & \\
\hline & 25,12174 & & & \\
\hline \multirow[t]{3}{*}{ DSC_0099.JPG } & 25,10643 & \multirow[t]{3}{*}{25,10214} & \multirow[t]{3}{*}{0,417062165} & \multirow[t]{3}{*}{ Yes } \\
\hline & 25,10435 & & & \\
\hline & 25,09565 & & & \\
\hline \multirow[t]{3}{*}{ DSC_0100.JPG } & 25,12231 & \multirow[t]{3}{*}{25,11940} & \multirow[t]{3}{*}{0,348589865} & \multirow[t]{3}{*}{ Yes } \\
\hline & 25,12231 & & & \\
\hline & 25,11359 & & & \\
\hline \multirow[t]{3}{*}{ DSC_0101.JPG } & 25,15033 & \multirow[t]{3}{*}{25,15385} & \multirow[t]{3}{*}{0,211922961} & \multirow[t]{3}{*}{ Yes } \\
\hline & 25,15033 & & & \\
\hline & 25,16090 & & & \\
\hline \multirow[t]{3}{*}{ DSC_0102.JPG } & 25,11343 & \multirow[t]{3}{*}{25,10763} & 0,395309185 & Yes \\
\hline & 25,09602 & & & \\
\hline & 25,11343 & & & \\
\hline DSC_0103.JPG & W $\quad 25,14161$ & CAP 25,14673 & 0,240195224 & Yes \\
\hline & 25,15032 & & & \\
\hline 9 & 25,14825 & & & \\
\hline DSC_0104.JPG & 25,15738 & 25,15517 & 0,206712824 & Yes \\
\hline & 25,15738 & & & \\
\hline 10 & 25,15074 & & & \\
\hline
\end{tabular}




\begin{tabular}{|c|c|c|c|c|}
\hline \multicolumn{5}{|c|}{ Group $P^{*} 66 * 3$} \\
\hline Specimen & Measurement (mm) & $\begin{array}{c}\text { Average } \\
(\mathrm{L} 1)\end{array}$ & $\mathrm{DC}(\%)$ & $\begin{array}{c}\text { Pass } \\
\text { (Yes/No) }\end{array}$ \\
\hline \multirow[t]{2}{*}{ IMG_3764.JPG } & 25,22433 & \multirow[t]{3}{*}{25,23054} & \multirow[t]{3}{*}{$-0,092288178$} & \multirow[t]{3}{*}{ Yes } \\
\hline & 25,23674 & & & \\
\hline 1 & 25,23054 & & & \\
\hline \multirow[t]{3}{*}{ IMG_3765.JPG } & 25,23559 & \multirow[t]{3}{*}{25,23766} & \multirow[t]{3}{*}{$-0,120533994$} & \multirow[t]{3}{*}{ Yes } \\
\hline & 25,23559 & & & \\
\hline & 25,24179 & & & \\
\hline \multirow[t]{2}{*}{ IMG_3766.JPG } & 25,30536 & \multirow[t]{3}{*}{25,30951} & \multirow[t]{3}{*}{$-0,405583997$} & \multirow[t]{3}{*}{ Yes } \\
\hline & 25,31781 & & & \\
\hline 3 & 25,30536 & & & \\
\hline \multirow[t]{2}{*}{ IMG_3767.JPG } & 25,25335 & \multirow[t]{3}{*}{25,25880} & \multirow[t]{3}{*}{$-0,204411901$} & \multirow[t]{3}{*}{ Yes } \\
\hline & 25,26087 & & & \\
\hline 4 & 25,26218 & & & \\
\hline \multirow[t]{2}{*}{ IMG_3768.JPG } & 25,28732 & \multirow[t]{3}{*}{25,29352} & \multirow[t]{3}{*}{$-0,342163148$} & \multirow[t]{3}{*}{ Yes } \\
\hline & 25,29973 & & & \\
\hline 5 & 25,29352 & & & \\
\hline \multirow[t]{3}{*}{ IMG_3769.JPG } & 25,25474 & \multirow[t]{3}{*}{25,25889} & \multirow[t]{3}{*}{$-0,204755717$} & \multirow[t]{3}{*}{ Yes } \\
\hline & 25,26096 & & & \\
\hline & 25,26096 & & & \\
\hline \multirow[t]{3}{*}{ IMG_3770.JPG } & 25,31964 & \multirow[t]{3}{*}{25,32007} & \multirow[t]{3}{*}{$-0,447476667$} & \multirow[t]{3}{*}{ Yes } \\
\hline & 25,32093 & & & \\
\hline & 25,31964 & & & \\
\hline \multirow[t]{3}{*}{ IMG_3772.JPG } & 25,27199 & \multirow[t]{3}{*}{25,27777} & $-0,279654735$ & Yes \\
\hline & 25,28311 & & & \\
\hline & 25,27820 & & & \\
\hline IMG_3773.JPG & W 25,30666 & CAP 25,30502 & $-0,387784901$ & Yes \\
\hline & 25,30666 & & & \\
\hline 9 & 25,30175 & & & \\
\hline IMG_3774.JPG & 25,26316 & 25,26774 & $-0,239864632$ & Yes \\
\hline & 25,27428 & & & \\
\hline 10 & 25,26577 & & & \\
\hline
\end{tabular}




\section{Addendum 5: Multiple comparisons}

LSD test; variable \%DC (Spreadsheet10)

Simultaneous confidence intervals

Effect: material*temperature*time

\begin{tabular}{|c|c|c|c|c|c|c|}
\hline $\begin{array}{l}\text { 1st - } \\
\text { Mean }\end{array}$ & $\begin{array}{l}\text { 2nd - } \\
\text { Mean }\end{array}$ & Mean - Differ. & $\begin{array}{c}\text { Standard - } \\
\text { Error }\end{array}$ & $\mathbf{p}$ & $\begin{array}{c}-95.00 \%- \\
\text { Cnf.Lmt }\end{array}$ & $\begin{array}{c}+95.00 \%- \\
\text { Cnf.Lmt }\end{array}$ \\
\hline $\mathrm{P} * 21 * 1$ & $\mathrm{P} * 21 * 2$ & -0.244235 & 0.042041 & 0.000000 & -0.328043 & -0.160428 \\
\hline $\mathrm{P}^{*} 21 * 1$ & $\mathrm{P}^{*} 21 * 3$ & 0.159119 & 0.042041 & 0.000316 & 0.075311 & 0.242926 \\
\hline $\mathrm{P} * 21 * 1$ & $\mathrm{P} * 66 * 1$ & -0.081843 & 0.044842 & 0.072125 & -0.171234 & 0.007547 \\
\hline $\mathrm{P} * 21 * 1$ & $\mathrm{P} * 66 * 2$ & -0.186228 & 0.044842 & 0.000089 & -0.275619 & -0.096838 \\
\hline $\mathrm{P} * 21 * 1$ & $\mathrm{P} * 66 * 3$ & 0.392534 & 0.044842 & 0.000000 & 0.303143 & 0.481924 \\
\hline $\mathrm{P} * 21 * 1$ & $\mathrm{~S}^{*} 21 * 1$ & 0.207166 & 0.044842 & 0.000016 & 0.117775 & 0.296556 \\
\hline $\mathrm{P}^{*} 21 * 1$ & $\mathrm{~S}^{*} 21 * 2$ & -0.117164 & 0.044842 & 0.010925 & -0.206554 & -0.027773 \\
\hline $\mathrm{P}^{*} 21 * 1$ & $S^{*} 21 * 3$ & 0.114301 & 0.044842 & 0.012935 & 0.024910 & 0.203691 \\
\hline $\mathrm{P}^{*} 21 * 1$ & $\mathrm{~S}^{*} 66 * 1$ & 0.214904 & 0.044842 & 0.000009 & 0.125514 & 0.304295 \\
\hline $\mathrm{P} * 21 * 1$ & $S^{*} 66 * 2$ & -0.176882 & 0.044842 & 0.000184 & -0.266272 & -0.087491 \\
\hline $\mathrm{P} * 21 * 1$ & $S * 66 * 3$ & 0.212939 & 0.044842 & 0.000010 & 0.123548 & 0.302329 \\
\hline $\mathrm{P} * 21 * 2$ & $\mathrm{P}^{*} 21 * 3$ & 403354 & 0.042041 & 0.000000 & 0.319546 & 0.487162 \\
\hline $\mathrm{P} * 21 * 2$ & $\mathrm{P} * 66 * 1$ & 0.162392 & 0.044842 & 0.000542 & 0.073002 & 0.251783 \\
\hline $\mathrm{P} * 21 * 2$ & $\mathrm{P} * 66 * 2$ & 0.058007 & 0.044842 & 0.199941 & -0.031383 & 0.147398 \\
\hline $\mathrm{P}^{*} 21 * 2$ & $\mathrm{P} * 66 * 3$ & 0.636769 & 0.044842 & 0.000000 & 0.547379 & 0.726160 \\
\hline $\mathrm{P} * 21 * 2$ & $S^{*} 21 * 1$ & 0.451401 & 0.044842 & 0.000000 & 0.362010 & 0.540791 \\
\hline $\mathrm{P} * 21 * 2$ & $\mathrm{~S}^{*} 21 * 2$ & 072 & 0.044842 & 0.005965 & 0.037681 & 462 \\
\hline $\mathrm{P} * 21 * 2$ & $\mathrm{~S}^{*} 21 * 3$ & 0.358536 & 0.044842 & 0.000000 & 0.269146 & 0.447927 \\
\hline $\mathrm{P} * 21 * 2$ & $S^{*} 66 * 1$ & 0.459139 & 0.044842 & 0.000000 & 0.369749 & 0.548530 \\
\hline $\mathrm{P} * 21 * 2$ & $S^{*} 66 * 2$ & 0.067354 & 0.044842 & 0.137464 & -0.022037 & 0.156744 \\
\hline $\mathrm{P}^{*} 21 * 2$ & $S^{*} 66 * 3$ & 0.457174 & 0.044842 & 0.000000 & 0.367784 & 0.546565 \\
\hline $\mathrm{P} * 21 * 3$ & $\mathrm{P}^{*} 66^{*} 1$ & -0.240962 & 0.044842 & 0.000001 & -0.330352 & -0.151571 \\
\hline $\mathrm{P} * 21 * 3$ & $\mathrm{P} * 66 * 2$ & -0.3 & 0.04 & 0.000000 & 738 & -0.255957 \\
\hline $\mathrm{P} * 21 * 3$ & $\mathrm{P}^{*} 66 * 3$ & 0.233415 & 0.044842 & 0.000002 & 0.144025 & 0.322806 \\
\hline $\mathrm{P} * 21 * 3$ & $\mathrm{~S}^{*} 21 * 1$ & 0.048047 & 0.044842 & 0.287534 & -0.041344 & 0.137437 \\
\hline $\mathrm{P} * 21 * 3$ & $S^{*} 21 * 2$ & -0.276282 & 0.044842 & 0.000000 & -0.365673 & -0.186892 \\
\hline $\mathrm{P} * 21 * 3$ & $S^{*} 21 * 3$ & -0.044818 & 0.044842 & 0.320918 & -0.134208 & 0.044573 \\
\hline $\mathrm{P}^{*} 21 * 3$ & $S^{*} 66 * 1$ & 35 & 0.0 & 7516 & 605 & 176 \\
\hline $\mathrm{P} * 21 * 3$ & $S^{*} 66 * 2$ & -0.336001 & 0.044842 & 0.000000 & -0.425391 & -0.246610 \\
\hline $\mathrm{P} * 21 * 3$ & $S^{*} 66 * 3$ & 0.053820 & 0.044842 & 0.233985 & -0.035570 & 0.143211 \\
\hline $\mathrm{P} * 66^{*} 1$ & $\mathrm{P}^{*} 66^{*} 2$ & -0.104385 & 0.042041 & 0.015362 & -0.188193 & -0.020577 \\
\hline $\mathrm{P} * 66 * 1$ & $\mathrm{P} * 66 * 3$ & 0.474377 & 0.042041 & 0.000000 & 0.390569 & 0.558185 \\
\hline $\mathrm{P} * 66 * 1$ & $S^{*} 21 * 1$ & 0.289009 & 0.044842 & 0.000000 & 0.199618 & 0.378399 \\
\hline $\mathrm{P}^{*} 66^{*} 1$ & $S^{*} 21 * 2$ & -0.035320 & 0.044842 & 0.433476 & 4711 & 0.054070 \\
\hline $\mathrm{P} * 66 * 1$ & $S^{*} 21 * 3$ & 0.196144 & 0.044842 & 0.000040 & 0.106754 & 0.285535 \\
\hline $\mathrm{P} * 66 * 1$ & $S^{*} 66 * 1$ & 0.296747 & 0.044842 & 0.000000 & 0.207357 & 0.386138 \\
\hline $\mathrm{P}^{*} 66^{*} 1$ & $S^{*} 66 * 2$ & -0.095039 & 0.044842 & 0.037504 & -0.184429 & -0.005648 \\
\hline $\mathrm{P} * 66 * 1$ & $S^{*} 66 * 3$ & 0.294782 & 0.044842 & 0.000000 & 0.205392 & 0.384173 \\
\hline $\mathrm{P} * 66 * 2$ & $\mathrm{P} * 66 * 3$ & 0.578762 & 0.042041 & 0.000000 & 0.494955 & 0.662570 \\
\hline $\mathrm{P} * 66 * 2$ & $S^{*} 21 * 1$ & 0.393394 & 0.044842 & 0.000000 & 0.304003 & 0.482784 \\
\hline $\mathrm{P} * 66 * 2$ & $S^{*} 21 * 2$ & 0.069065 & 0.044842 & 0.127899 & -0.020326 & 0.158455 \\
\hline $\mathrm{P} * 66 * 2$ & $\mathrm{~S}^{*} 21 * 3$ & 0.300529 & 0.044842 & 0.000000 & 0.211139 & 0.389920 \\
\hline $\mathrm{P} * 66 * 2$ & $S^{*} 66^{* 1}$ & 0.401132 & 0.044842 & 0.000000 & 0.311742 & 0.490523 \\
\hline
\end{tabular}




\begin{tabular}{|c|c|c|c|c|c|c|}
\hline $\mathrm{P} * 66 * 2$ & $S^{*} 66 * 2$ & 0.009346 & 0.044842 & 0.835480 & -0.080044 & 0.098737 \\
\hline $\mathrm{P} * 66 * 2$ & $S^{*} 66 * 3$ & 0.399167 & 0.044842 & 0.000000 & 0.309777 & 0.488558 \\
\hline $\mathrm{P} * 66 * 3$ & $S^{*} 21 * 1$ & -0.185368 & 0.044842 & 0.000095 & -0.274759 & -0.095978 \\
\hline $\mathrm{P}^{*} 66^{*} 3$ & $S^{*} 21 * 2$ & -0.509698 & 0.044842 & 0.000000 & -0.599088 & -0.420307 \\
\hline $\mathrm{P}^{*} 66^{*} 3$ & $S * 21 * 3$ & -0.278233 & 0.044842 & 0.000000 & -0.367623 & -0.188842 \\
\hline $\mathrm{P} * 66 * 3$ & $S^{*} 66^{*} 1$ & -0.177630 & 0.044842 & 0.000173 & -0.267020 & -0.088239 \\
\hline $\mathrm{P}^{*} 66^{*} 3$ & $S^{*} 66 * 2$ & -0.569416 & 0.044842 & 0.000000 & -0.658806 & -0.480025 \\
\hline $\mathrm{P} * 66 * 3$ & $S * 66 * 3$ & -0.179595 & 0.044842 & 0.000149 & -0.268985 & -0.090204 \\
\hline$S^{*} 21 * 1$ & $\mathrm{~S} * 21 * 2$ & -0.324329 & 0.042041 & 0.000000 & -0.408137 & -0.240522 \\
\hline$S^{*} 21 * 1$ & $S^{*} 21 * 3$ & -0.092865 & 0.04 & 0.030365 & -0.176672 & -0.009057 \\
\hline$S^{*} 21 * 1$ & $S^{*} 66^{*} 1$ & 0.007738 & 842 & 0.863471 & 1652 & 7129 \\
\hline$S^{*} 21 * 1$ & $S^{*} 66 * 2$ & -0.3 & 0.0 & 0.0 & -0.4 & 4657 \\
\hline$S^{*} 21 * 1$ & $S^{*} 66 * 3$ & 0.005773 & 0.044842 & 0.897913 & -0.083617 & 0.095164 \\
\hline$S * 21 * 2$ & $S * 21 * 3$ & 0.231465 & 0.042041 & 0.000001 & 0.147657 & 0.315272 \\
\hline$S^{*} 21 * 2$ & $S^{*} 66^{*} 1$ & 0.332068 & 0.044842 & 0.000000 & 0.242677 & 0.421458 \\
\hline$S^{*} 21 * 2$ & $S^{*} 66 * 2$ & -0.059718 & 0.044842 & 0.187143 & -0.149109 & 0.029672 \\
\hline$S * 21 * 2$ & $S^{*} 66 * 3$ & 103 & & 0.000 & 712 & 4993 \\
\hline$S^{*} 21 * 3$ & $S^{*} 66^{*} 1$ & 0.1 & 0.04 & 0.027941 & 0.01 & 0.189994 \\
\hline$S^{*} 21 * 3$ & $S^{*} 66^{*} 2$ & -0.291183 & 0.044842 & 0.000000 & -0.380573 & -0.201792 \\
\hline$S * 21 * 3$ & $S * 66 * 3$ & 0.098638 & 0.044842 & 0.031040 & 0.009248 & 0.188029 \\
\hline$S^{*} 66 * 1$ & $S^{*} 66 * 2$ & -0.391786 & 0.042041 & 0.000000 & -0.475594 & -0.307978 \\
\hline$S^{*} 66^{*} 1$ & $S^{*} 66 * 3$ & -0.001965 & 0.042041 & 0.962849 & -0.085773 & 0.081843 \\
\hline$S^{*} 66 * 2$ & $S^{*} 66 * 3$ & 0.389821 & 0.042041 & 0.000000 & 0.306013 & 0.473629 \\
\hline
\end{tabular}




\section{Addendum 6: Descriptive Statistics}

\begin{tabular}{|c|c|c|c|c|c|c|c|c|c|}
\hline \multirow[b]{2}{*}{ Effect } & \multicolumn{9}{|c|}{ Descriptive Statistics (Spreadsheet10) } \\
\hline & $\begin{array}{l}\text { Level of } \\
\text { Factor }\end{array}$ & $\begin{array}{l}\text { Level of } \\
\text { Factor }\end{array}$ & $\begin{array}{c}\text { Level of } \\
\text { Factor } \\
\end{array}$ & $\mathrm{N}$ & $\begin{array}{l}\text { \%DC } \\
\text { Mean }\end{array}$ & $\begin{array}{c}\text { \%DC } \\
\text { Std.Dev. }\end{array}$ & $\begin{array}{c}\text { \%DC } \\
\text { Std.Err }\end{array}$ & $\begin{array}{c}\% \mathrm{DC} \\
-95.00 \% \\
\end{array}$ & $\begin{array}{c}\% \mathrm{DC} \\
+95.00 \% \\
\end{array}$ \\
\hline Total & & & & 120 & 0.078971 & 0.217153 & 0.019823 & 0.039719 & 0.118223 \\
\hline material & $\bar{P}$ & & & 60 & 0.113631 & 0.248617 & 0.032096 & 0.049406 & 0.177855 \\
\hline material & $\mathrm{S}$ & & & 60 & 0.044311 & 0.175661 & 0.022678 & -0.001067 & 0.089689 \\
\hline temperature & 21 & & & 60 & 0.100324 & 0.174444 & 0.022521 & 0.055260 & 0.145387 \\
\hline temperature & 66 & & & 60 & 0.057618 & 0.252492 & 0.032597 & -0.007608 & 0.122843 \\
\hline time & 1 & & & 40 & 0.035132 & 0.185570 & 0.029341 & -0.024217 & 0.094480 \\
\hline time & 2 & & & 40 & 0.301315 & 0.079066 & 0.012501 & 0.276029 & 0.326602 \\
\hline time & 3 & & & 40 & -0.099535 & 0.133566 & 0.021119 & -0.142252 & -0.056818 \\
\hline material*temperature & $\mathrm{P}$ & 21 & & 30 & 0.148560 & 0.182890 & 0.033391 & 0.080268 & 0.216853 \\
\hline material*temperature & $\mathrm{P}$ & 66 & & 30 & 0.078701 & 0.299631 & 0.054705 & -0.033183 & 0.190585 \\
\hline material*temperature & $\mathrm{S}$ & 21 & & 30 & 0.052087 & 0.153778 & 0.028076 & -0.005335 & 0.109509 \\
\hline material*temperature & $\mathrm{S}$ & 66 & & 30 & 0.036534 & 0.197496 & 0.036058 & -0.037212 & 0.110280 \\
\hline material*time & $\mathrm{P}$ & 1 & & 20 & 0.161110 & 0.175565 & 0.039258 & 0.078943 & 0.243277 \\
\hline material*time & $\mathrm{P}$ & 2 & & 20 & 0.335420 & 0.073274 & 0.016384 & 0.301127 & 0.369713 \\
\hline material`time & $\mathrm{P}$ & 3 & & 20 & -0.155638 & 0.158969 & 0.035547 & -0.230038 & -0.081238 \\
\hline material*time & $\mathrm{S}$ & 1 & & 20 & -0.090847 & 0.080314 & 0.017959 & -0.128435 & -0.053259 \\
\hline material*time & $\mathrm{S}$ & 2 & & 20 & 0.267211 & 0.070811 & 0.015834 & 0.234070 & 0.300352 \\
\hline material`time & $\mathrm{S}$ & 3 & & 20 & -0.043432 & 0.068711 & 0.015364 & -0.075590 & -0.011274 \\
\hline temperature*time & 21 & 1 & & 20 & 0.016605 & 0.133432 & 0.029836 & -0.045843 & 0.079053 \\
\hline temperature*time & 21 & 2 & & 20 & 0.300888 & 0.082701 & 0.018492 & 0.262183 & 0.339593 \\
\hline temperature*time & 21 & & & 20 & -0.016522 & 0.075892 & 0.016970 & -0.052040 & 0.018997 \\
\hline temperature*time & 66 & 1 & & 20 & 0.053658 & 0.228382 & 0.051068 & -0.053228 & 0.160544 \\
\hline temperature*time & 66 & 2 & & 20 & 0.301743 & 0.077409 & 0.017309 & 0.265515 & 0.337972 \\
\hline temperature*time & 66 & 3 & & 20 & -0.182548 & 0.127873 & 0.028593 & -0.242395 & -0.122702 \\
\hline material*temperature*time & $P$ & 21 & 1 & 10 & 0.120188 & 0.059507 & 0.018818 & 0.077619 & 0.162757 \\
\hline material*temperature*time & $\mathrm{P}$ & 21 & 2 & 10 & 0.364424 & 0.064329 & 0.020343 & 0.318406 & 0.410442 \\
\hline material*temperature*time & $\mathrm{P}$ & 21 & 3 & 10 & -0.038931 & 0.091504 & 0.028936 & -0.104388 & 0.026527 \\
\hline material*temperature ${ }^{\star}$ time & $\mathrm{P}$ & 66 & 1 & 10 & 0.202031 & 0.240434 & 0.076032 & 0.030035 & 0.374028 \\
\hline material*temperature*time & $\mathrm{P}$ & 66 & 2 & 10 & 0.306417 & 0.072987 & 0.023080 & 0.254205 & 0.358628 \\
\hline material*temperature*time & $\mathrm{P}$ & 66 & of th 3 & 10 & -0.272346 & 0.121282 & 0.038353 & -0.359105 & -0.185586 \\
\hline material*temperature*time & $S$ & 21 & 1 & 10 & -0.086977 & 0.101006 & 0.031941 & -0.159233 & -0.014722 \\
\hline material*temperature ${ }^{\star}$ time & 51 & 21 & 2 & 10 & 0.237352 & 0.036468 & 0.011532 & 0.211264 & 0.263440 \\
\hline material*temperature ${ }^{\star}$ time & $\mathrm{S}$ & 21 & 3 & 10 & 0.005887 & 0.051674 & 0.016341 & -0.031078 & 0.042852 \\
\hline material*temperature*time & $\mathrm{S}$ & 66 & 1 & 10 & -0.094716 & 0.058153 & 0.018390 & -0.136316 & -0.053116 \\
\hline material*temperature ${ }^{\star}$ time & $S$ & 66 & 2 & 10 & 0.297070 & 0.085290 & 0.026971 & 0.236057 & 0.358083 \\
\hline material*temperature*time & $\mathrm{S}$ & 66 & 3 & 10 & -0.092751 & 0.043492 & 0.013753 & -0.123863 & -0.061639 \\
\hline
\end{tabular}

